\title{
Plenary Session 4: \\ Georisks and \\ Geo-Resources
}

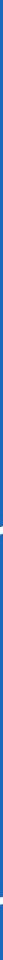




\section{Introduction}

\author{
Presentation: Hans-Peter Bunge
}

The Alps owe their existence to the convergence of the African and European plates. Their beautiful setting is the result of tectonic forces that acted for millions of years. The very same forces, however, that helped to build the mountains also created a landscape of great fragility where natural hazards are concentrated. Earthquakes, landslides, flooding and the dramatic response of glaciers and permafrost to an accelerating climate change pose serious threats to the safety of the region and its cities. These dangers are made all the more potent by the concentration of the population into the major Alpine valleys, a high degree of industrialization and rather low preparedness. While today earth scientists monitor and model the hazard relevant processes in the atmosphere, the soil and aqueous systems and in the ground beneath at far greater accuracy than before, there is a need to communicate their findings to the broader public and policy makers in order to prevent a "disaster gap" and a loss of traditional disaster memory that was handed down from one generation to the next.

In this session we seek a dialogue between earth scientists and policy makers. We focus on earthquake hazards, for which there is low preparedness, and for which a serious mitigation effort would require to initiate and install a common strategy for long-term earthquake protection that treats the Alps as a single tectonic region. The associated earthquake threat must be seen by all Alpine countries as a common problem requiring joint approaches and common solutions. We also explore hazards that follow from the increasingly evident consequences of climate change. These manifest themselves prominently in the Alpine region in the form of glacial retreat, loss of permafrost areas and the ever more frequent occurrence of severe storms and floods. Climate change requires a reorientation in our energy policies. Therefore the use of geothermal energy becomes an important issue of future energy supply. Professor Hüttl, director of the Geozentrum Potsdam (GFZ), will highlight the newly established International Center for Geothermal Research (ICGR), which holds an internationally leading role in developing reliable geothermal technologies and innovative concepts of a sustainable economic energy supply. Under GFZ-leadership a number of large scale geothermal experiments have been performed at Groß Schönebeck and Ketzin which are relevant to geothermal resource exploration in the Alpine region. 


\title{
Earthquakes in Alpine Regions - a Threat to Our Cities!
}

\author{
Domenico Giardini
}

The Alps are the result of the collision of the African and Eurasian plates over the last 100 million years. The beautiful mountains which characterize the Alps are the direct results of this compression over geological times, and the main Alpine valleys are located along the scars left by the suture zones and faults which built the Alps. One sign and at the same time an important building mechanism of the tectonic activity still shaping the Alpine compression are the earthquakes. The Alpine region has a long history of earthquakes along its whole arc, from the French coast all the way to Slovenia. Earthquakes brought destruction throughout history, adding to the many other hazards affecting this region.

In discussing the threat posed by earthquakes to our modern cities and Alpine environment, we need to consider different aspects.

\section{Earthquake Hazards}

Earthquakes occur frequently and in all regions of the Alps. If we consider only the Swiss Valais region, every 80 to 100 years we record the occurrence of a large damaging earthquake of the same magnitude as the Friuli earthquake of 1976 or the recent L'Aquila earthquake of 2009. In addition, earthquakes in the Alpine region are mostly very shallow, due to the rheological and temperature conditions of the lower crust, occurring mostly in the first ten kilometers below the surface. As such, their effects are felt locally and strongly.

A defining element of the Alpine panorama are the valleys, deeply excavated by glacial erosion. A typical Alpine valley - i.e. the Rhone valley - is filled by up to $1 \mathrm{~km}$ of fluvial sediments, characterized by very low velocity of seismic waves, sur-

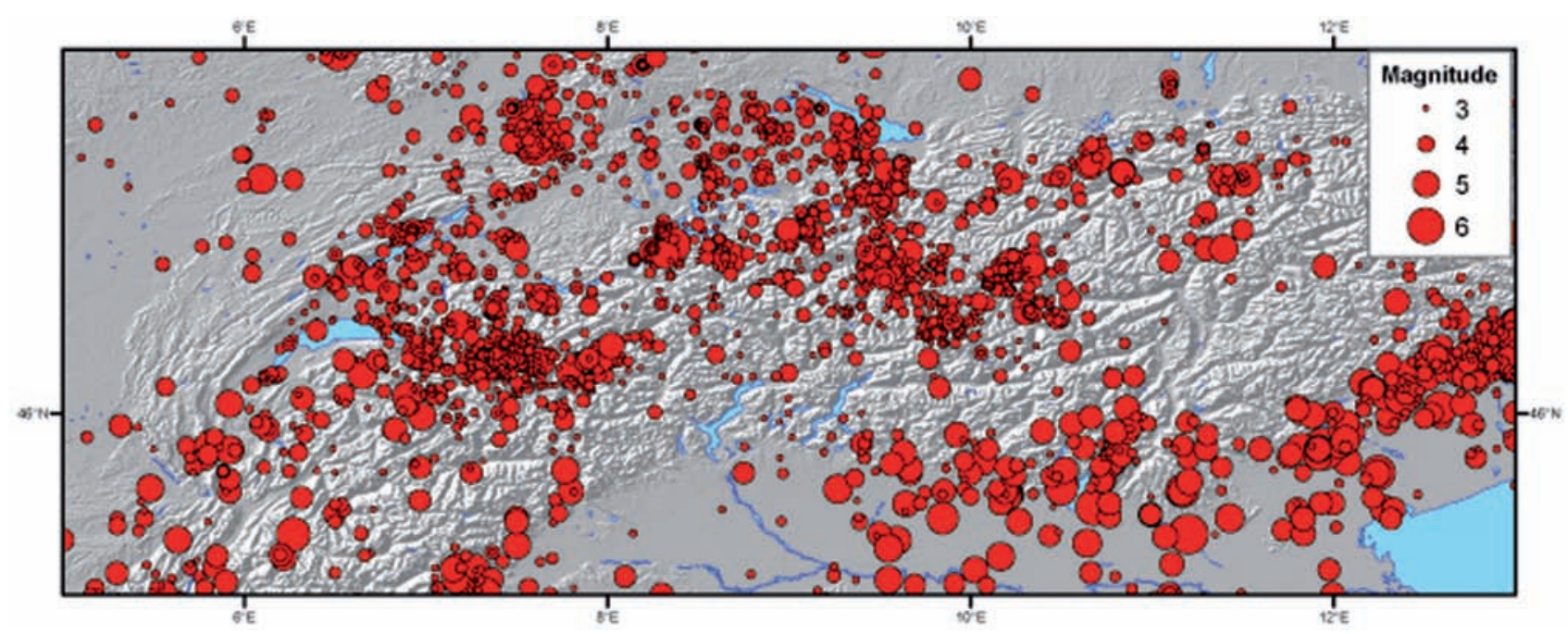

Fig. 1: Seismicity of the central Alpine region from the year 1000 to the present, extracted from the Earthquake Catalogue of Switzerland (ECOS 2009, in publication). 
rounded by the hard rock of the Alps. Seismic waves slow down and increase in amplitude when they enter the loose sediments, and the resulting shaking on the sediments can be ten times longer and ten times higher than on rock; as a result, when a site on rock on the valley flank feels the shaking of a magnitude 5 event, a nearby site on the valley bottom will experience the effects of a magnitude 6 .

Finally, shaking will induce hazardous gravitational effects such as landslides on the mountain flanks and liquefactions in the sediments, worsening the effects of the earthquake. which have been recognized as unsuitable for urbanization, due to liquefaction and non-linear effects in the sediments observed after past earthquakes.

- Seismic norms in the building codes are not obligatory in all the Alpine region; in addition, seismic norms are calibrated for a 500 year earthquake hazard, which may not cover the larger earthquakes, occurring every few thousand years.

- Corrections are applied in the building code to account for the difference between sediments and rock; these corrections, however, do not cover

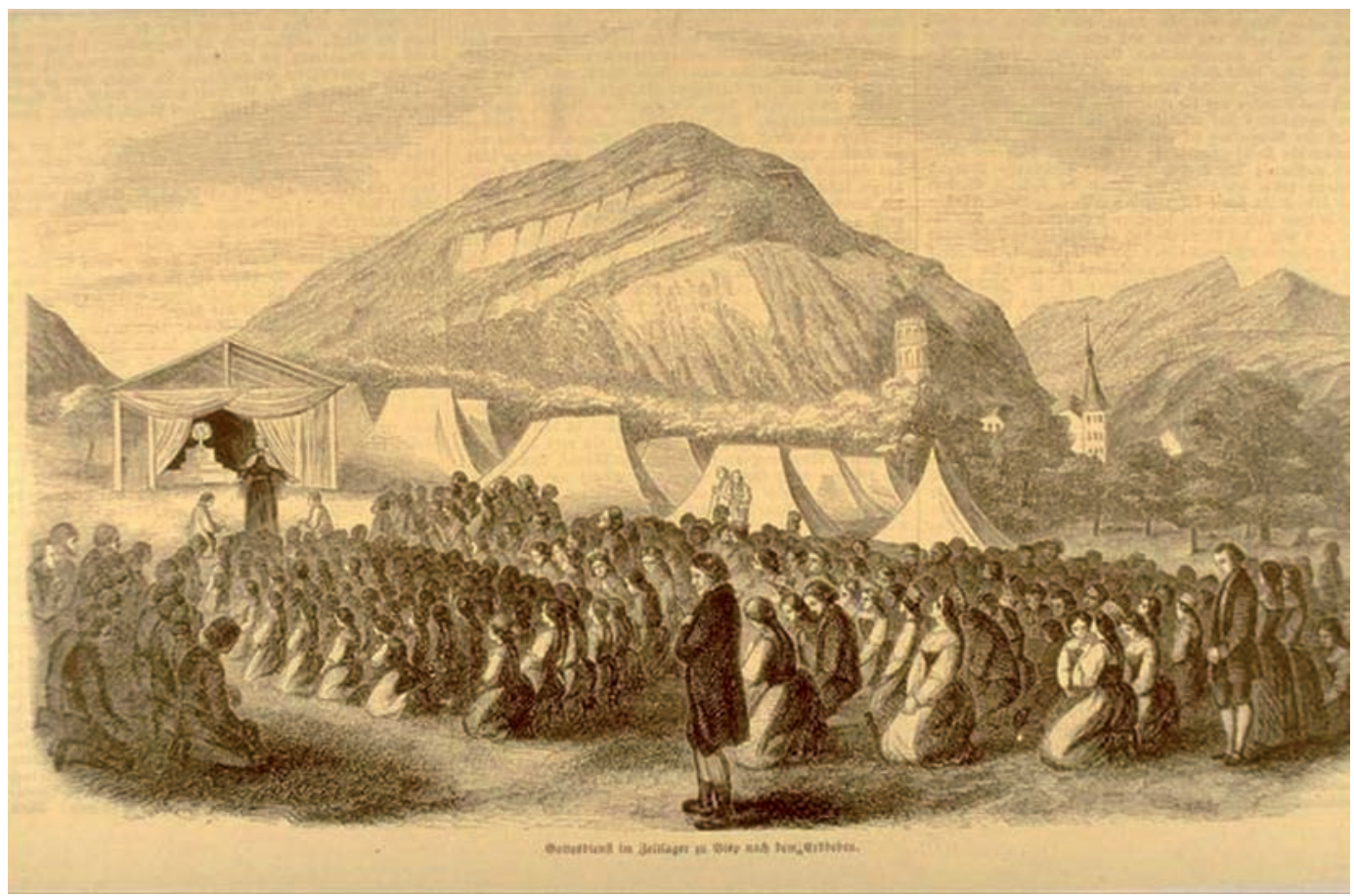

Fig. 2: The population of Visp (Valais, Switzerland) hosted in tents following the 1855 M6.3 earthquake.

\section{Increasing Urbanization}

In modern times, all important functions of our society concentrate more and more in cities: in addition to the largest part of the population, we find in cities all the administration, the main communication nodes, the industry and other crucial functions such as schooling and security. This is even more so in the Alps, where valleys provide the only possibility for significant growth of population and thus for cities to expand. The growth of cities and the concentration of critical functions have been so pronounced in the last century that historical earthquakes can only provide an indication of how modern cities in the Alps would resist an earthquake.

When discussing earthquakes and urbanization, we need to consider three aspects:

- For lack of alternatives, cities have been allowed to expand on the valley floors, also in areas the large amplifications produced by the trapping of seismic waves in the sedimentary layers inside steep Alpine valleys.

\section{Risk Perception and Mitigation}

Our society is becoming less and less able and willing to accept risks - natural and man-made. Protection from natural hazards is a major investment for all Alpine regions and cities, and concentrates on those hazards which occur more frequently, such as flooding, avalanches and landslides. It is inherently more difficult to install long-term mitigation policies against earthquakes, which may strike a city every few hundred or thousand years. And yet, a large earthquake will strike a wide area, very often across borders, and involving several cities and villages, with a level of widespread destruction which is unmatched by other natural hazards. 

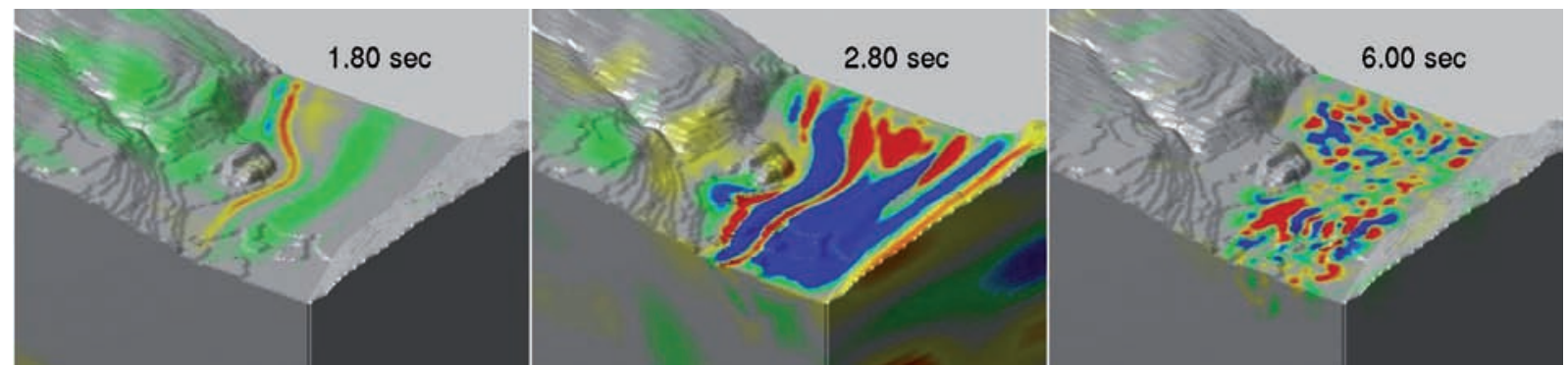

Fig. 3: Snapshot images of the simulated ground shaking which would be produced by an earthquake in the central Rhone valley of Switzerland (Sion, Switzerland). The shaking is simulated using a full 3 D model and calibrated using observed seismic waveforms from recent earthquakes. The shaking inside the sedimentary valley is much longer and much stronger than in the surrounding mountain rocks.

For a serious mitigation effort, it would be time to initiate and install a common strategy for longterm earthquake protection, based on different, complementary actions:

- a common monitoring and alert system, building on the existing regional and national networks and allowing a coordinated response to the occurrence of an earthquake

- a common earthquake hazard mapping programme, covering the whole area and including the mapping of the effects of the sedimentary valleys

- a common earthquake risk assessment programme, focusing on the assessment and inventory of earthquake vulnerability for buildings and critical structures across the whole Alps and on scenario modeling for shaking, damage and socioeconomic risk for the main cities of the Alpine region

- common standards in building codes and protection measures

- a coordinated programme of research and development in seismology, tectonics and earthquake engineering.

The key to future protection of our cities lies in our capacity of treating the Alps as a single tectonic region and the associated earthquake threat as a common problem requiring joint approaches and common solutions.

\section{References}

Global Earthquake Model (GEM): www.globalquakemodel.org

Seismic Hazard Harmonization for Europe (SHARE):

www.share-eu.org

Gisler, M., D. Faeh \& D. Giardini (eds.) (2008): Nachbeben: historische Erdbeben in der Schweiz. Haupt Verlag, Bern.

Wiemer, S., D. Giardini, D. Faeh et al. (2009): Probabilistic Seismic Hazard Assessment of Switzerland: Best Estimates and Uncertainties. Journal of Seismology 13/4: 449-478, doi:10.1007/s10950-008-9138-7 (Oct 2008). 


\section{Geothermal Technology}

\author{
Reinhard F. J. Hüttl
}

The use of geothermal energy becomes an important issue of future energy supply within strategies for the mitigation of climate changes. The International Center for Geothermal Research (ICGR) meets this challenge by developing reliable geothermal technologies and innovative concepts of a sustainable economic energy supply. ICGR covers research in a holistic approach along the whole chain of geothermal technologies from the geothermal reservoir to the provision of power, heat, and chill. Especially, the center is focused to reduce risks and costs of geothermal exploration and exploitation and to expand accessible reservoirs addressing most of European and worldwide geological settings. The center offers a close interface between research and industry bundling international geothermal expertise and experience in a global geothermal network based on self-developed large scale hands on projects which plot the whole process for a geothermal energy supply.

The ICGR is embedded in the GFZ, which has a strong expertise in subsurface geological research linked to pure and applied geothermics. Expertise is developed in the characterisation of the Earth's thermal field and its controlling factors such as the mode of heat transfer, thermal rock properties, and geodynamic processes. The determination and interpretation of the terrestrial heat flow is one major focus in the interpretation of thermal fields. Also in the focus of research are coupled thermo-hydraulicmechanical processes and their expression in the development of man-made geothermal reservoirs.

A major part of recent research is the link with Germany's EGS lighthouse projectGroßSchönebeck, in which, as part of the reservoir exploration, 3D structural geological models are developed based on newly defined workflows in unconventional 3D geological mapping integrating pre-existing data from 2D seismics, wells, maps and expert knowledge. Well logs are used to parameterize the geological models and to characterize the geothermal reservoir. The 3D geological models, in which all available geodata (including data from exploration geophysics) are integrated, aid in the comprehensive understanding of the local as well as regional structures of the geosystem and build the basis for the reservoir engineering, e.g. for flow simulations and for a successful access of the reservoir target zone by directional drilling. Expert knowledge is being built on assessing wellbore stability and on understanding mechanical failure processes at borehole scale by using the combined approach of fracture mechanics and structural geology. Present research is also focused on reservoir geomechanical modelling and on stress field analysis owing to the significant impact of in situ stresses on the short-term and long-term behaviour of fractured reservoirs. Thus, the reservoir geomechanics is investigated by 3D fault mapping and slip-tendency analysis to understand the fault reactivation potential and the fracture-controlled fluid flow processes in man-made geothermal reservoirs.

GFZ has a brought expertise in reservoir engineering as a key issue for geothermal technology and $\mathrm{CO}_{2}$ storage. Under the GFZ-leadership a number of large scale experiments were performed in the boreholes of Groß Schönebeck and Ketzin following the goal of optimum economic utilization of reservoirs. All this is done by adequate planning including reservoir modelling and understanding of the processes and interaction of the system "borehole - reservoir". As a result of large scale experiments experiences are yielded by engineering the productivity of reservoirs by stimulation 
treatments. Several concepts have been developed to enhance the existing productivity, which can be summarized by the terms hydraulic fracturing, thermally induced fracturing and chemical stimulation. Hydraulic fracture stimulations such as waterfrac treatments, gel-proppant treatments, and a combination of both called hybrid treatments were performed. The procedures are well known in hydrocarbon industry as well as in the Hot Dry Rock (HDR) technology. GFZ developed these techniques further for specific requirements of hydrothermal reservoirs with special stimulation techniques in order to produce considerably higher amounts of fluids compared to hydrocarbon reservoirs.

The subjects which were addressed include characterisation of reservoir parameters from laboratory experiments as well as borehole measurements to monitor the reservoir characteristics. The aim is to study long-term hydraulic flow, rock-fluid interaction, mechanical-hydraulic and thermal-hydraulic coupled processes, recent stress field and borehole stability. In conjunction with operational work the above mentioned issues support mitigation strategies to avoid reservoir and storage impairment and hence lead to productivity increase and sustainability during the later use.

The Geothermal In Situ Laboratory at Groß Schönebeck was completed with a second deep borehole (1/2007) applying new approaches to drill large diameters, realising concepts of directional drilling, and using mud concepts to minimise damage of the target reservoir. In accordance with demands of running and upcoming projects GFZ has already developed and constructed its novel InnovaRig for scientific and geothermal purposes. This is complemented by several specific scientific instruments such as slimhole geophysical borehole logging sondes, long-term monitoring instruments, petrophysical core and cutting analyses instruments and the appropriate data management systems. All of these are integrated or developed with major international Earth science programmes such as the ICDP.

Recently the ICGR started to develop sustainability concepts for the exploitation of geothermal reservoirs in Indonesia - capacity building and methodologies for site deployment. The collaboration in methodology and technology development in combination with a training programme will support capacity building in geothermal technologies in Indonesia.

In addition, engineering to integrate the mitigation of induced seismicity IS in Geothermal Reservoirs is done in order to analyse IS from geothermal reservoirs, to understand the geomechanics and processes involved in IS, to assess the consequences of IS and develop and propose strategies for the mitigation of IS. 


\title{
Damage Caused by Natural Disasters: Trends in Europe with a Focus on the Alps
}

\author{
Peter Höppe, Wolfgang Kron
}

\section{Introduction}

Several dramatic weather catastrophes have occurred in the Alps during the last twenty years: extreme rainfall over large areas occurred in 1994, 1999, 2000, and 2005, resulting in floods, landslides and debris flows. In the spring of 1999, avalanches posed a serious threat to people for several weeks. Houses and trees collapsed under heavy snow loads in large parts of Austria and Bavaria in the winter of 2006, killing several dozen people. In January 2007, winter storm Kyrill ravaged forests, causing the second-highest financial loss by any storm in Europe.

\section{Observed Loss Trends}

Munich Re's Geo Risks Research department has been collecting loss reports associated with natural events throughout the world in its NatCatSERVICE database for over 35 years. Now numbering more than 28,000 , the events are continuously analysed and the results published (e.g. Munich Re 2010).

Nine natural catastrophes in the Alps have so far caused financial losses exceeding more than one billion US dollars (Tab. 1). In this context, the "Alps" are defined in line with the area covered by the Alpine Convention (STMUG 2010). Figure 1 shows a significant upward trend in the annual number of loss

\begin{tabular}{|c|c|c|c|c|c|}
\hline \multirow{2}{*}{ Period } & \multirow{2}{*}{ Event } & \multirow{2}{*}{ Affected Area } & Overall losses & Insured losses & \multirow{2}{*}{ Fatalities } \\
\hline & & & \multicolumn{2}{|c|}{ US $\$ \mathrm{~m}$, original values } & \\
\hline $4-6.11 .1994$ & Floods, flash floods & Italy & 9,300 & 65 & 70 \\
\hline $13-20.10 .2000$ & Floods, landslides & |ttaly. Switzerland. France & 8,500 & 480 & 40 \\
\hline 18-20.1.2007 & Winter Storm Kyrill & Germany. Austria. Switzerland. Slovenia & 5,900 & 3,260 & 15 \\
\hline $4-13.8 .2002$ & $\begin{array}{l}\text { Floods, severe } \\
\text { storms }\end{array}$ & Germany. Italy & 3,600 & 25 & \\
\hline $20-28.8 .2005$ & Floods & Austria. France. Germany & 3,260 & 1,780 & 10 \\
\hline $12-20.8 .2002$ & $\begin{array}{l}\begin{array}{l}\text { Floods, severe } \\
\text { storms }\end{array} \\
\end{array}$ & Austria. Switzerland & 2,410 & 400 & 9 \\
\hline 23-24.7.2009 & $\begin{array}{l}\text { Severe storms, } \\
\text { hailstorms }\end{array}$ & Austria. Germany. Switzerland & 1,600 & 1,015 & 1 \\
\hline 26.12.1999 & Winter Storm Lothar & Italy. Switzerland. Austria & 1,550 & 800 & 10 \\
\hline $23.9-1.10 .1993$ & Floods & Italy. Switzerland & 1,045 & 240 & 10 \\
\hline $1-2.3 .2008$ & $\begin{array}{l}\text { Winter Storm Emma, } \\
\text { storm surge }\end{array}$ & Austria. Switzerland & 600 & 310 & 4 \\
\hline
\end{tabular}

Tab. 1: The Ten Costliest Natural Catastrophes in the Alps from 1980 to 2009. 


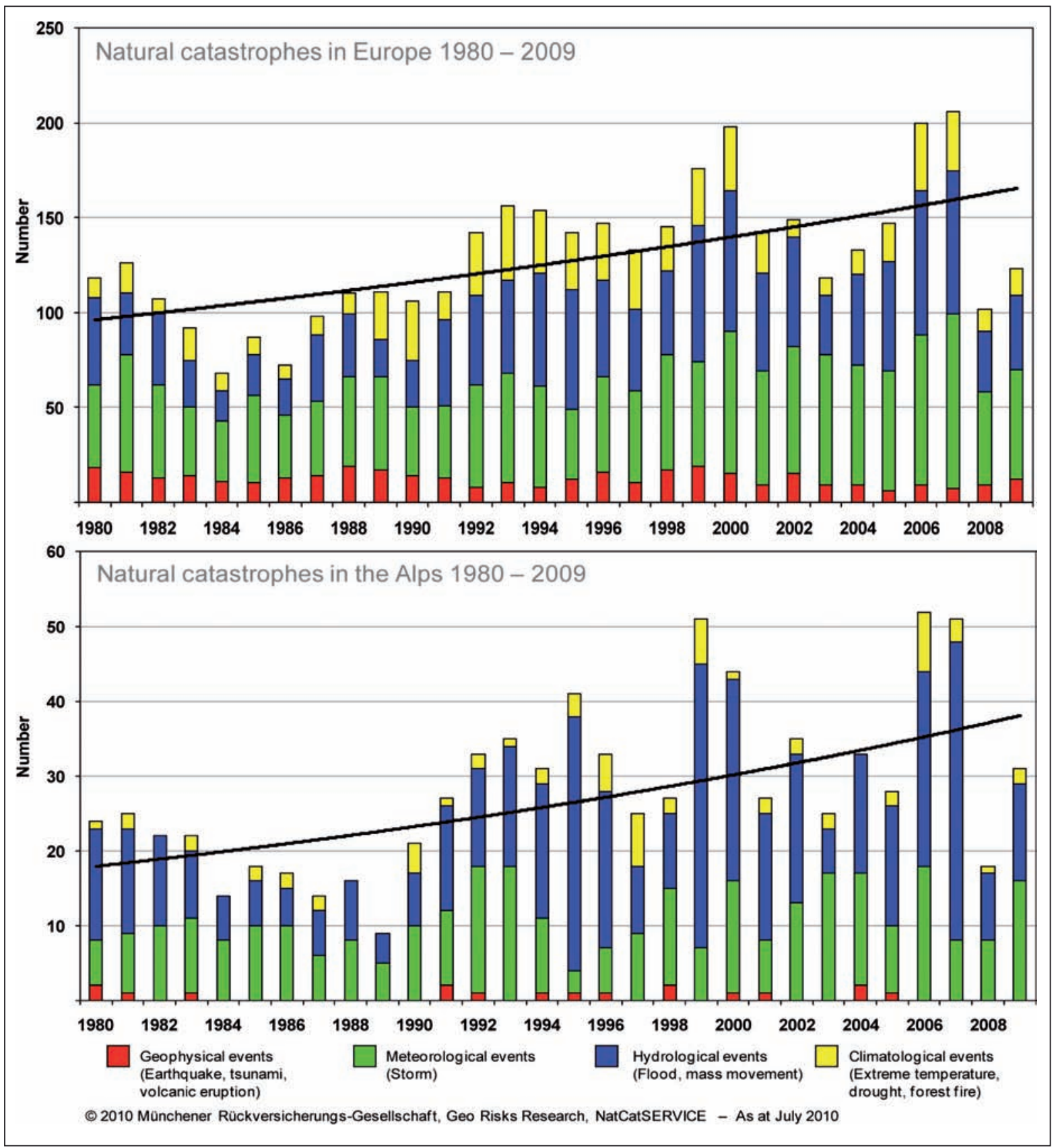

Fig. 1: Number of Natural Catastrophes in Europe and the Alps in the Period 1980-2009.

(Note: The region "Alps" is defined according to the Alpine Convention cooperation area (STMUG 2010)).

events in the past 30 years, both in the whole of Europe and in the Alps. However, the trend is stronger in the Alpine area than for the continent as natural catastrophes in the Alps are almost exclusively caused by weather events. They are responsible for almost $100 \%$ of all natural catastrophes in the Alps; geophysical causes, such as earthquakes, have been negligible in the recent past; they have accounted for only about $2 \%$ of all events since 1980 . In addition: not only the number of weather-related catastrophes, but also the losses which they have inflicted on the national economies of Europe and the insurance industry have risen sharply in recent decades (Fig. 2). Is this rise due to climate change, a process which already appears to be emerging more quickly in the Alps?

\section{Where is the Danger Emanating from?}

Windstorms are the commonest cause of natural catastrophes in Central Europe (Munich Re 2008). However, most of the built-up Alpine areas (valleys) tend to be less exposed to winter storms than more northerly regions. This is because the Alps are located fairly far inland, so that the winter storms coming in from the Atlantic have in many cases al- 


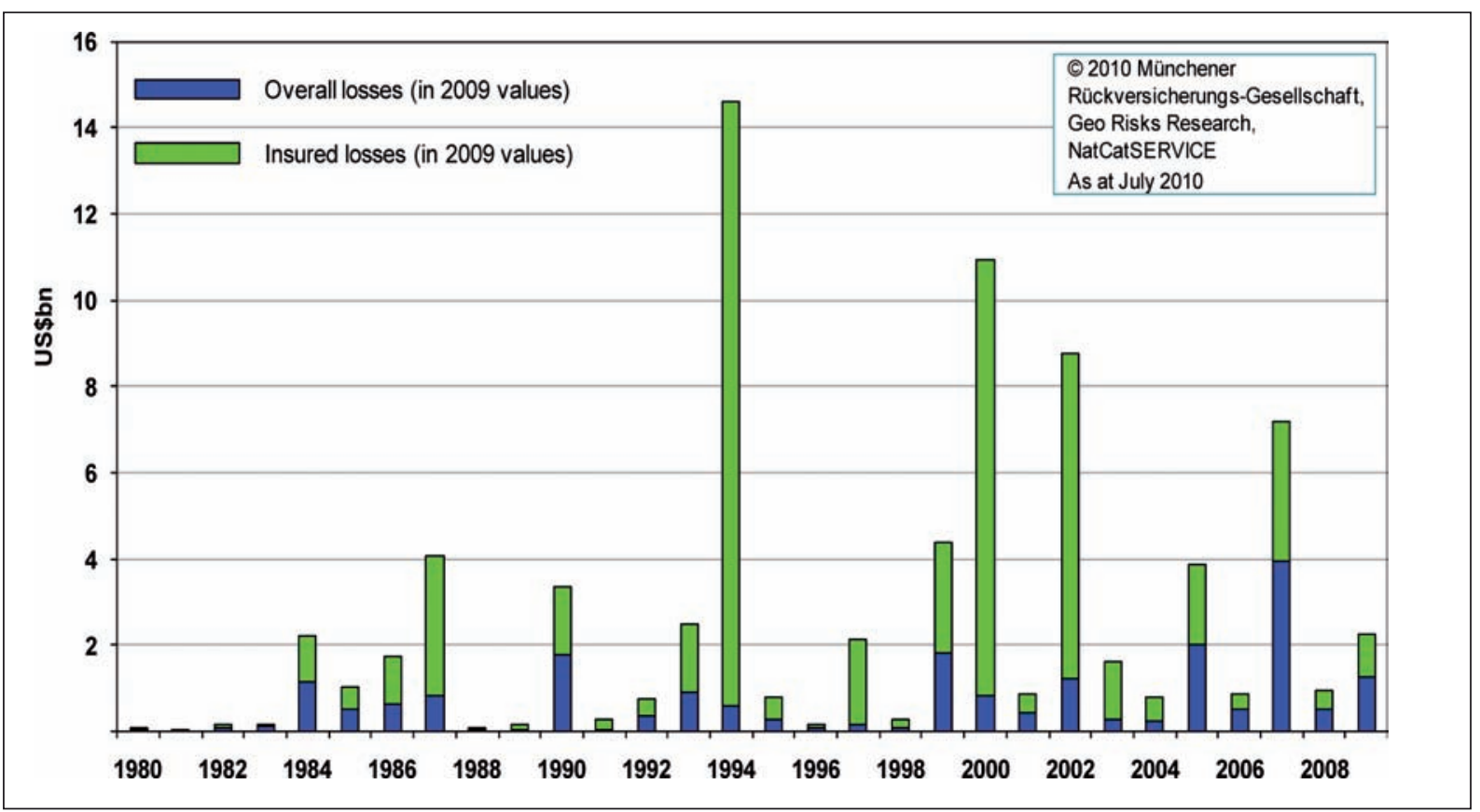

Fig. 2: Overall and Insured Losses of Weather Catastrophes in the Alps in the Period 1980-2009.

ready eased up. Secondly, the considerable surface roughness created by the mountains has a damping effect on wind speeds, although this does not mean that gusts of wind cannot be locally amplified as a result of jet effects. The damping effect is weaker at higher altitudes - this is particularly noticeable in the forests. Winter storm Kyrill, for example, destroyed thousands of hectares of mountain forest in the region around Berchtesgaden and in Austria. Foehn storms also have the potential to cause damage and must not be underestimated, although they do not develop anything like the geographical size and destructive force of winter storms.

River floods, defined as a flood wave building up over a period of several days of persistent rain, are unknown in the Alps. This is because the characteristics of mountain streams and alpine rivers are completely different from those of rivers on plains. Mountain floods are consequently more in the nature of flash floods, even when large rivers are involved. The water rises extremely quickly due to the mostly high intensity of precipitation entering the water-courses very rapidly in the steep catchment areas.

High flow rates in steep terrain can potentially cause considerable erosion and transport of solids. This means that structures may suffer scouring resulting in total loss. Rocks, gravel, sand and earth are often carried along by the water, generally aggravating the damaging effect through mechanical forces, as well as through dirt and deposits. Although debris flows and the other mass movements typical of mountain regions, such as land- slides, rockfalls and slope creeping, are in part due to geological factors, they are usually triggered by weather events. Together with glacial lake outbursts and ice fall, they have the greatest destructive potential. However, they only occur locally and therefore only cause damage over a limited area. Losses can to a large extent be avoided by respecting the hazard zones which, in most countries, are mapped or at least known. A number of spectacular occurrences in Switzerland in the summer of 2006 (rockfalls on the St. Gotthard and the Eiger mountains, glacial lake outburst in Samedan) focused public attention on the consequences of climate change in the mountains. One thing is certain: glaciers recede even more quickly in a warmer climate and the permafrost thaws. Slopes may be destabilised, forming more loose material which is then carried into the valleys by landslides and debris flows following torrential rain.

The danger due to avalanches is comparable with that of the sudden mass movements mentioned above. Avalanches in the extreme winter 1998/1999 killed 79 people in the Alps. Although this catastrophe was perceived as exceptional at the time (due largely to extensive media reports on a few spectacular cases - notably Galtür), it "only" caused an economic loss of roughly 800 million euros. By far the greatest part of the insured losses was incurred by Switzerland, where private avalanche losses are mostly insured; these catastrophes cost the insurance industry almost 200 million euros here.

Snowstorms, frost and ice rain are hazards with potentially immense consequences which are often underestimated. After a number of years with rela- 
tively little snow in the more recent past, however, the winter of 2005/2006 showed that the danger due to snow load is by no means a thing of the past. Heavy snow fell several times in Austria and Bavaria, the massive snow load damaging not only forests, but also buildings. Roofs caved in; schools, shopping centres, businesses, sports halls and hotels had to be evacuated and churches closed. The economic loss totalled half a billion euros in Austria and 100 million euros in Bavaria.

Heat waves and dry spells, such as those experienced in the summer of 2003 , tend to affect mountain areas to a lesser extent. Water resources for drinking water and hydropower, however, will be threatened as glaciers disappear.

\section{Why Are the Losses Increasing?}

Back in 1973, Munich Re was "one of the first warning voices in the industry" to point out in a publication on river floods (Munich Re 1973) that anthropogenic climate change may be one of the driving factors leading to greater losses. The warnings and statements published by Munich Re for more than thirty years have been confirmed by the Fourth Assessment Report of the Intergovernmental Panel on Climate Change (IPCC 2007): climate change will lead to more extreme weather events and consequently to higher costs. All climate models predict warmer, wetter winters with considerably less snow (on average) in Central Europe. The higher content of water vapour in the atmosphere will not only lead to more rainfall in general, but also to regional and local storm situations with more extreme rain intensities. Precipitation will become more variable, with an increase in extreme weather conditions. Particularly the westerly pressure systems with their flood potential will become more numerous and the intensity of precipitation from Central and Western European trough weather systems will increase, transporting immense quantities of moist air towards the Alps from the Mediterranean. On the north side of the Alps, these will form the widely feared $\mathrm{Vb}$ lows which are responsible for most of the catastrophic floods here. The trend towards drier summers in certain regions does not necessarily mean relief as regards torrential summer rainfall, as it will be concentrated on fewer days with high rain intensity resulting in more flash floods.

The losses are caused by extremes, not by rising or falling mean values. However, the cause of natural catastrophes is not solely attributable to the magnitude of the natural event, but also and above all to the inability of an affected region to react. Existing assets (settlement density) and their physical vulnerability are just as important as the various protective measures, both structural (flood protection, construction, etc.) and organisational (land use regulations, building codes, warning systems, emergency relief, insurance, etc.). The assets which can be destroyed by natural catastrophes have become enormously more concentrated and higher, in the Alps as everywhere. Since the development of new settlement areas is already limited by orographic conditions, settlements often expand into areas prone to flooding, avalanches, landslides and rockfalls. The hazards to which they are consequently exposed are supposedly eliminated by protective structures or consciously accepted at first and then forgotten if nothing happens.

Flood control and avalanche protection have no doubt reduced losses in many regions most effectively in recent decades. At least part of the increase in losses has been compensated in this way. The efficacy of measures taken to prepare for a catastrophe is shown by the activities which were stepped up following the Whitsun flood in Bavaria in 1999. The flood in 2005 affected many of the same towns and villages as six years earlier, but all concerned - authorities and general public - had learned from the past. The technical guards had been improved in many areas and steps taken to permit more efficient catastrophe management. Moreover, the memory of dealing with such a catastrophe had not yet faded, with the result that both the authorities and individuals were able to act more efficiently. As a result, the flood caused only half as much damage as the last time.

Such an experience, however, must not be seen as an indication that "all will go well" in the future too. Floods, inundations and losses will recur. It is therefore important to make people aware that a residual risk always remains, and that they must adjust to that risk and live with it. The assumed compensatory effect may disappear one day and it is likely that climate change will intensify the losses to a greater extent in future - regardless of developments in assets and settlements. At the same time, we may safely assume that a great deal more will be invested in technical systems for tourists in the future, for instance to compensate the lack of snow for winter tourists - another direct consequence of climate change.

\section{Risk Management}

Efficient protection against catastrophes, including loss minimisation, can only be achieved through integrated and concerted action in the form of a risk partnership. The burden of precautionary measures and alleviation of the overall risk must be borne by many shoulders. The state (i.e. all public institutions) is responsible for basic protection (observation and warning systems, protection against frequent losses, statutory requirements with regard to land use, building regulations, etc.) and for 
providing emergency relief during and after a crisis. The individuals who may be affected (people and firms) must bear their share of the precautionary measures (property protection, management of assets, behaviour). In fact, this risk partnership is of decisive importance. The insurance companies, finally, must indemnify the financial loss which may afflict or even ruin the insured parties. With a view to assessing the risk - and particularly the risk of inundation - insurance associations in Germany, Austria and Italy have made a significant contribution in recent years with the development of the zoning systems ZÜRS, HORA and SIGRA, respectively. Loss trends are of course also taken into account in the insurance companies' pricing, with the result that insurance cover inevitably becomes more expensive with increasing risk. One positive effect could be that policy-holders will seek to reduce their risk through preventive measures in order to reduce their insurance costs at the same time.

In the Alps, a single major event can cause losses in the region of several billions of euros. The floods along the Austrian tributaries on the left bank of the Danube in August 2002 cost more than three billion euros. A centre of precipitation further south could also cause devastating flooding along the Danube itself - for instance in cities such as Linz and even Vienna. The 2005 floods in central Switzerland, the worst in the country's history, caused losses of more than two billion euros. Two thirds of these were insured. And the loss could be even higher - in the order of several billion euros - if it were to strike the more highly industrialised metropolitan areas of Zurich and Basel.

\section{Summary}

Natural catastrophes in the Alps have become more frequent and will continue to do so. Governments, emergency relief services, the general public and the insurance industry must adjust to the fact that the number of occurrences will increase, with more catastrophic effects and higher losses overall. On the other hand, there have always been occasional extremes. By themselves, such exceptional weather events consequently cannot be taken as proof of changes in the climate. Only the sum of their - more frequent - occurrence can serve as proof. Insurances play an important part in ensuring protection against extremes of nature, particularly as part of a strategy of adapting to climate change. They not only spread part of the risk over many shoulders, but can also contribute to the decisive step of encouraging individuals and the private sector in general to take precautionary measures, heightening their awareness of the risk and indeed making it their duty. Precautions must be taken in the form of a suitable mixture of struc- tural, organisational (e.g. warnings) and financial (insurance) measures, while governments must ensure comparable, i.e. fair, basic protection for everyone throughout the region.

The most effective precautionary measure is to avoid building in hazard-prone areas. Municipalities must give up the idea of developing land for construction in high-risk areas. Changes due to global warming are emerging particularly early and in particularly striking form in the Alps. Just like the insurance industry, which is the first to register changes in the claims burden, the Alpine region acts as a "global early warning system" showing the consequences of climate change.

\section{References}

STMUG (2010): http://www.stmug.bayern.de/english/ europe/reg_alpkonv.htm (extr. July 19, 2010).

IPCC (2007): Climate Change 2007: Fourth Assessment Report of the Intergovernmental Panel on Climate Change http://www.ipcc-data.org/ddc_ar4pubs.html

Munich Re (1973): Flood - Inundation. Munich Re, München.

Munich Re (2008): Highs and Lows - Weather Risks in Central Europe. Knowledge Series, Munich Re, München.

Munich Re (2010): Topics Geo Natural Catastrophes 2009, Munich Re, München. 


\title{
The "Disaster Gap" of the 2oth Century and the Loss of Traditional Disaster Memory
}

\author{
Christian Pfister
}

Nature induced disasters are commonly understood as sudden outbreaks of the forces of nature, which within a short time have a large destructive impact on humans and their artefacts. Scholars have increasingly come to accept that nature induced disasters should be understood as both physical events and socio-cultural occurrences. This is not easy because many social scientists are not familiar with scientific methods and thinking. Natural scientists, on the other hand, are not acquainted with cultural studies and the theories of human agency needed to deal with the cultural side of disasters. Historical Climatology tries to bridge this gap between the physical and the cultural dimensions of disaster. This research field is situated at the interface of climatology and (environmental) history, dealing mainly with documentary evidence and using the methodology of both climatology and history.

The term collective memory coined by the French sociologist Maurice Halbwachs defines a memory achievement of a group of people. In particular, he mentions family memory which draws on everyday oral communication. It is biologically restricted to 3 generations. Memories reaching further back are supported by documents such as newspaper cutouts and photo albums. In contrast, cultural memory defined by Jan Assmann as the "outer dimension of human memory" is a collective term including the entirety of knowledge which governs our behaviour. It is always supported by media and handed down from one generation to the next in order to be practised. Whether a collective and/or a cultural memory of past disasters is still active in people's mind mainly depends on disaster frequency.

Systems of disaster avoidance and risk communication were well developed in traditional societies. Rivers followed a natural course which changed after major floods. Bank protection was not efficient before the mid 19th century; therefore, the low lying land along the rivers was extensively used communal ground without any buildings. Some settlements in the Alps were shielded against avalanches from the late Middle Ages by so-called "ban forests" benefiting from a special protection status. Systems of early warning in case of impending floods were already well developed in 18th-century Upper Engadin (Switzerland): Guards were appointed who had to monitor the river Inn at night. If the water became destructive, they alerted the village population. In such cases there was a well-rehearsed division of tasks according to gender. Men assisted in reinforcing the river embankments whereas women snatched up the valuable belongings and drove the cattle uphill to safe places. In late 15th century Basel, a squad was called up on the bridge in case of an impending flood of river Rhine. These men had the task to take out drifting logs from the floods in order to prevent the bridge from being damaged. Quite often, the squad was not applied. This strategy was introduced after an extreme flood in July 1480. Undoubtedly, this is a learning effect which, however, fell into oblivion in the mid 16th century when severe floods were not frequent for some decades. The culture of knowledge about climatic risk was communicated through flood marks placed on public or private buildings. According to the insurance industry, the risk of a natural hazard is perceived all the more higher as individuals or parts of society remember a comparable event. An assemblage of the frequency and severity of floods exposed in the public sphere allowed getting a kind of risk awareness which mirrors the 
term of risk used by the insurance industry which is the likelihood of a damage of a certain importance to occur.

Forgetting like remembering chiefly originates from the experience of the individual. The collective and the cultural memory are selective. What is inscribed in the cultural memory is kept, indeed, but exogenous impulses are needed to initiate the process of remembrance. If such impulses do not occur for some time, the remembrance fades out and the applied knowledge of coping with disasters is lost through non-use.

During the 2oth century the traditional cultures of risk including their memoria felt into oblivion. Most flood marks were destroyed and the centennial of severe events was not any more mentioned worked out for the period 1800-2007. The monetary losses of a past disaster were expressed in terms of a number of mason's daily wages for the same year. This number was then reconverted into Swiss Francs of 2000 by multiplying the number of daily wages with the appropriate wage in the year 2000. Of course, this approach only yields an approximate result, but it remains the only way to define disasters of equal severity. For the graph 300 million francs of 2000 or 50 victims were taken as a threshold.

The graph only shows the monetary values caused by "natural disasters". Between 1806 and 1881650 people were killed by natural hazards, mostly by the two rockfalls of Goldau (1806) and Elm (1881). The average amount of annual losses

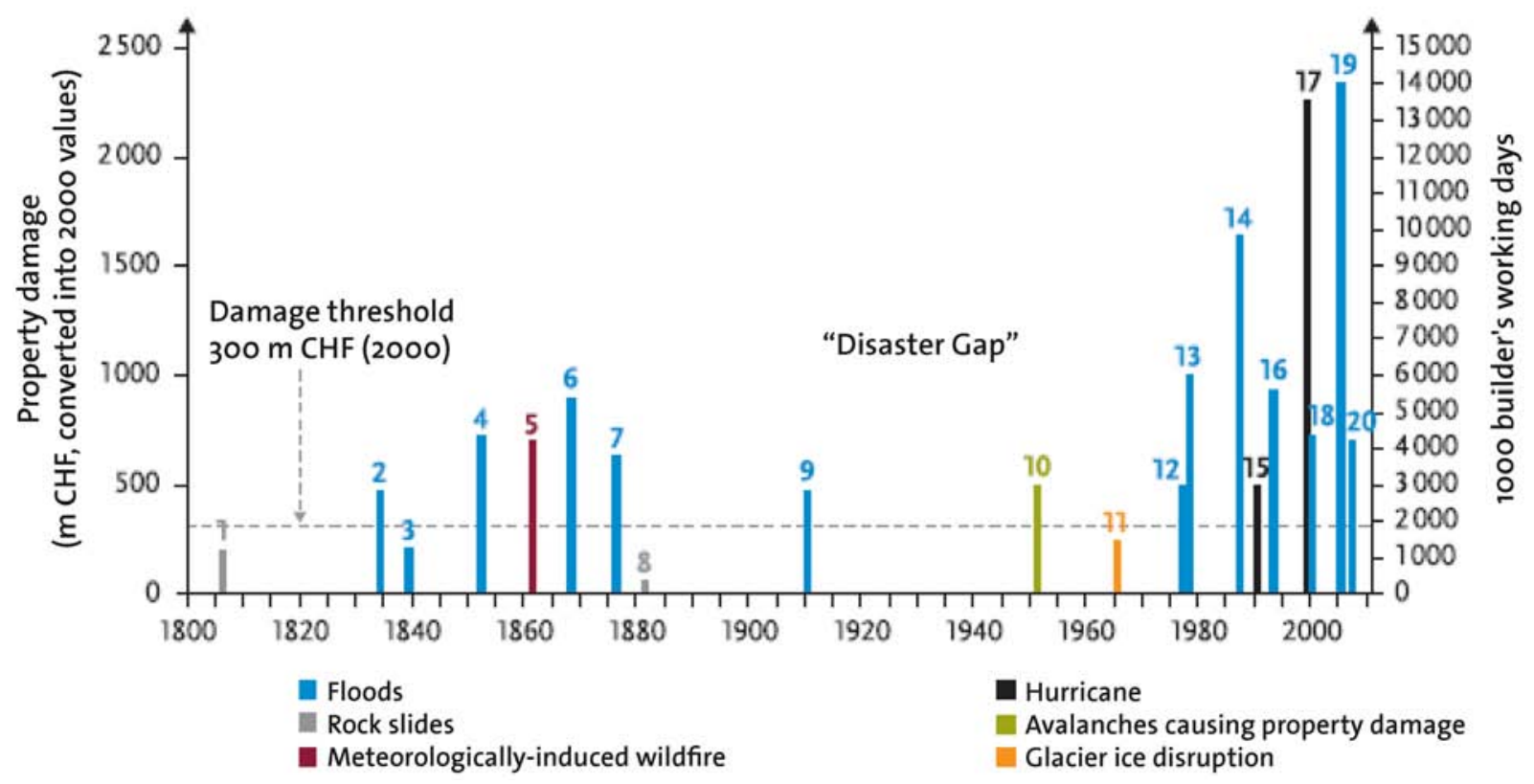

The „Disaster Gap“ in Switzerland, 1882-1976.

in the media. An obvious line of interpretation would relate this tendency to the introduction of natural hazard insurance, the availability of new rescue technologies (e.g. bulldozers, helicopters) or cultural change. However, the development over the last 30 years has demonstrated that primarily the needed impulses in the form of severe hazards were lacking: Indeed, between 1882 und 1976, i.e. almost during a century, severe disasters did almost not occur in Switzerland.

The severity of a disaster depends on two parameters, namely the number of victims and the amount of monetary losses. While the number of victims may be compared over time, the amount of losses in the past needs to be converted to present day monetary values. For Switzerland, this homogenization problem was solved in the following way. A series of mason's daily wages was reached 42 million francs of 2000, mostly through severe floods and the fire of Glaris (1861) promoted by violent Föhn winds. Between 1882 and 1976 213 people were killed, most of them through avalanches in the winter of 1950/51 and through the glacier break up in Mattmark (1965). Average monetary losses were four times smaller than in the preceding phase. From 1977 to 2008 the number of disaster victims was reduced to 40 . On the other hand, monetary losses skyrocketed to 343 million francs of 2000, which is 34 times more than in the preceding period. This increase results from a much higher number of severe cases, rapid urbanisation and a higher value density.

The disaster gap, the non-occurrence of extreme hazards, mostly floods, during almost a century is a significant element for explaining the loss of cultural memory. This interpretation is underlined by 
the fact that the extreme increase in the frequency and severity of disasters over the last 30 years has contributed to the reappearance of a new vigorous culture of risk which even includes a revival of the memory of historical disasters.

\section{References}

Pfister, Ch. (ed.) (2002): Am Tag danach. Zur Bewältigung von Naturkatastrophen in der Schweiz 1500-2000. Haupt, Bern.

Pfister, Ch. (2009): Die Katastrophenlücke des 20. Jahrhunderts und der Verlust traditionalen Risikobewusstseins. GAIA Ecological Perspectives for Science and Society 3/18: 239-246.

Pfister, Ch. (2009): Learning from Nature-induced Disasters. Considerations from Historical Case Studies in Western Europe. In: Mauch Ch. \& Ch. Pfister (eds.): Natural Disasters, Cultural Responses: Case Studies Toward a Global Environmental History. Lexington Books, Lanham: 17-40.

Pfister, Ch. (2010): "Mind the Next Flood". Applied Risk Management and Disaster Memory in Western Europe 17002000. RCC Perspectives, forthcoming.

Pfister, Ch., J. Luterbacher, H. Wanner et al. (2009): Documentary Evidence as Climate Proxies. Proxy-specific White Paper produced from the PAGES/CLIVAR Workshop, Trieste. In: PAGES (Past Global Changes), http://www.pages-igbp. org/cgi-bin/WebObjects/products.woa/wa/product?id=331

Studer, R. \& P. Schuppli (2008): Deflating Swiss Prices over the Past Five Centuries. Historical Methods 41/3: 137-156. 


\title{
Risk and Migration Processes: the Friuli Earthquake of 1976 - From Profound Fear to New Immigration
}

\author{
Mauro Pascolini
}

Among the many territorial aspects of the spatial processes of reconstruction after a disaster, leaving out those related to the immediately organized rescue phase and to the early interventions, the most involved are those that highlight the dynamics of the population according to more strictly demographic variables and those related to spatial and settlement type. In particular, during and after a disaster with highly destructive features, such as those of the earthquakes, the affected population individually and collectively carries out spatial actions closely related to mobility. In fact, it's common that people temporarily leave the place of the disaster epicentre, but, in some cases, when the disaster is particularly intense and affects a large area, this abandonment takes on the characteristics of a real exodus that can be transformed from a temporary situation to a final emigration.

With reference to these aspects, the 1976 Friuli earthquake is an interesting case of study because it highlighted not only the significant movements of the population during the different post-impact stages, but also, for the territory affected, largely mountainous and hilly, and for the choices made during the reconstruction process, it confirmed the trends that were already present in the social and economic dynamics of Friuli.

More than thirty years after the earthquake, it's possible to propose an assessment of territorial and social dynamics that, together, led the areas affected by the earthquake to the current situation which is the result of traditional evolutionary dynamics similar to other areas that transformed from rural into industrial, combined with those resulting from a traumatic acceleration of these processes.

\section{The Event}

On May 6, 1976 at nine p.m., a shock having an intensity of 6.5 Richter rocked a huge area for nearly a minute (Figs. 1-2), starting from the epicentre located near Gemona del Friuli. Some summary data: 137 municipalities were involved within a range of 219 of the entire region, with a population of over half a million inhabitants. 100,000 were dead, 3,000 injured, 100,000 homeless, 157,000 houses were damaged and 32,000 houses destroyed. Damage costs amounted to 4,500 billion Lire (2,300 million euros).

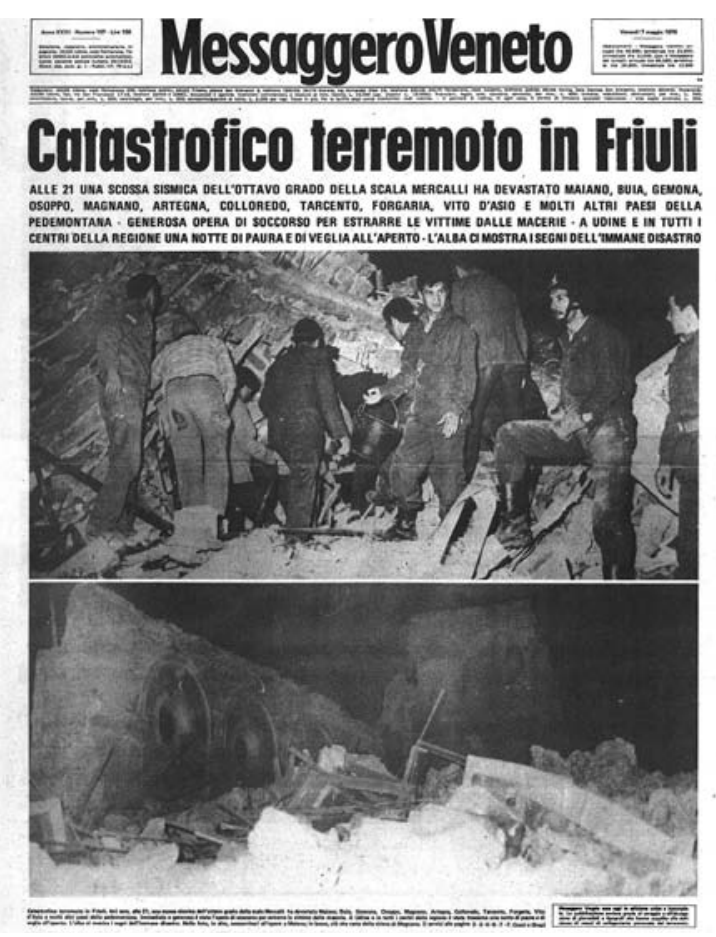

Fig. 1: Friuli appears on the coversheet of the newspapers (Archive Messaggero Veneto). 
One peculiarity of the earthquake in Friuli, which decisively influenced the subsequent reconstruction that was undertaken a few months later, was another earthquake. In fact, on 11 September there were two shocks (5.1 and 5.6 Richter) and on 15 September two more (5.8 and 6.1 Richter). This time span of seismic events prevented the immediate commencement of the reconstruction process because, after these shocks, about 80,000 people were displaced mainly throughout the tourist resorts on the Adriatic coast of Friuli and Veneto and in those areas, always touristic, belonging to the Friulian mountains; and there they remained until the following spring when the slums were completed near the affected countries.

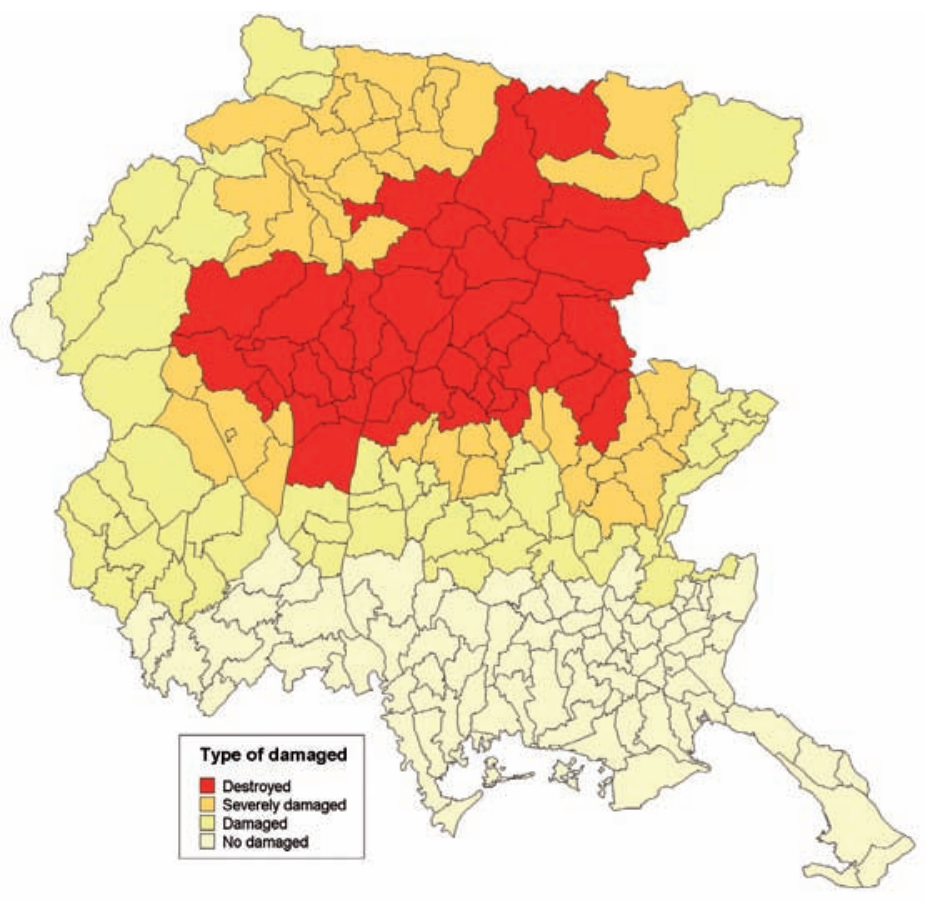

Fig. 2: The Areas Affected by the 1976 Earthquake by Type of Damage.

\section{Friuli: Past and Present}

A quick ID card: Friuli-Venezia Giulia covers an area of about 7,800 sq km of which $42.6 \%$ is mountainous area and $19.3 \%$ is foothill and has a population of just fewer than 1,225,000 inhabitants. Throughout history, its particular geographical position fostered the establishment and development of a rural society characterized by the presence of different ethnic groups (Friulian, Italian, Slovenian and German). From a demographic point of view it should be noted that the growth was particularly significant in the last century until the 1960s, a fact that fuelled, taking into account the weakness of the economy, massive migration flows that decreased only at the end of the 1970s. Today, the drop in the birth rate and the aging population, among the highest in Italy, are the dominant features of the regional demographic dynamics, especially in mountainous and remote areas, while entering flow migrations are significant.

The area affected by the earthquake in those years was involved in a demographic decrease, highlighted by a population escape to the strong centres of the Po Valley and to the neighbouring European countries; the most important mountain centres decayed, the population aged significantly, agriculture played a far greater role and, finally, the nascent industrial development was concentrated in certain areas and, at the same time, dispersed in small production units within the area.

The settlement was characterized by a series of small and medium towns, very widespread in the territory. The appearance was that of a network of rural villages with typical stone houses of river pebbles, arranged in short, with rustic outbuildings. To summarize, the spatial organization, the urban structure and the scenic frame were typical for a countryside which for centuries had been the backbone of the economy.

\section{Udine: "Big" but Disappeared}

The most important goal of reconstruction was to give a home to all families affected by the earthquake in a wider area compared to the previous one. The issues of many administrators were manyfold; they were not only of a practical nature, but

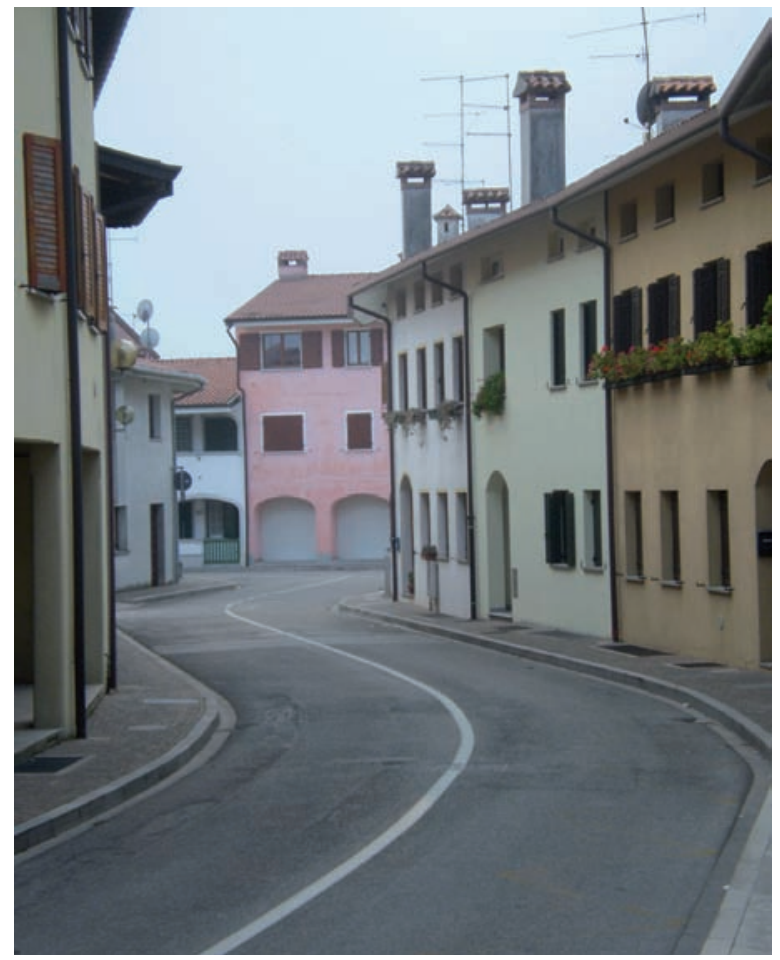

Fig. 3: Reconstruction Not Always Complied with the Above Types. 
especially related to the fundamental choices of localization. The regional government, according to the information coming from the population, abandoned the idea, initially proposed, to build a "big" Udine, thus solving the problem of spatial dispersion and the weakness of the mountain region. Udine did not even reach 100,000 inhabitants, so it did not seem strange to imagine a new city that could become quite comparable to an average city of the Po valley, thus giving response to the already apparent trend of mountain depopulation and of the population decrease and, simultaneously, finally establishing a centre of urban size with all related services according to major administrative and management functions.

It was decided instead also because of the strong pressure of the earthquake victims to rebuild their countries (if possible, with the same types of buildings) and to restore all the buildings that were least damaged. Thus was born the slogan of Friuli reconstruction: Where it was and how it was.

If, today, where it was has been achieved, we cannot say the same for how it was, which had always been more a hope than a choice really carried out. The results are easily verifiable and visible (Fig. 3), as the typological change was determined by several factors: the desire to have a more beautiful and comfortable home, the fast-thinking and sometimes culturally incompetent designers, some ideological choices related to planners and design models and different and sometimes conflicting interpretations of restoration significance. It should also be noted that, in many cases, more was rebuilt than necessary, especially in the more marginal peripheral and mountainous centres, where houses were restored even in absence of a stable population.

\section{Fearing the Big Escape}

One of the themes that arose immediately after the catastrophe was that of emigration and, in particular, the fear that the earthquake would start again the migration flows that in that period had ceased to characterize Friuli, and had always been considered similar to other Italian regions, a privileged reservoir of workforce to be used in Italy or abroad.

In fact, Friulian migration history took place over a very broad period of time ranging from the 16th century to the middle of the 1970s, when, for the first time, the social balance was positive. By 1800 , migration flows began to take on consistent and permanent emigration patterns, next to seasonal ones; not only the inhabitants of the mountains, but also those of the plain participated in this process. By the late 19th and early 2oth century the great period of Friulian emigration began with annual rates of emigration which ranged from $4 \%$ to $8 \%$.

Emigration became increasingly common, thus depopulating irreversibly more marginal areas of the mountain, the foothills and even the weaker areas of the plains. A variety of professionals fuelled the migration flows that formed the Friuli population abroad, which today is estimated to be increasing by approximately one million people (immigrants and descendants of them) with each passing generation.

The fact that there was another Friuli outside the geographic one worried the managers of the reconstruction because the strong relationships with the motherland and the close family networks could somehow reactivate emigration, which had permanently expired. But the "great fear" of a mass migration did not materialize because some important factors came into play that limited the phenomenon to a series of cases of little significance, even in the aftermath of the fateful exodus to the coastal centres.

The first factor is that people chose to focus on the reconstruction of the productive apparatus in the belief that only through economic recovery and, thus, production of income would people stay in their communities and would individual reconstruction costs of houses be payable. On the one side, this allowed some of the existing industrial areas to be strengthened, on the other to make them more modern and competitive by creating a significant small economic boom in Friuli. This choice was made easier because the connection was provided daily, with an efficient public transport network from the exodus areas where there were the administrative and social structures of the individual municipalities to those premises of industrial and manufacturing plants.

It's clear that an important and partly anomalous role was carried out by the construction sector that expanded beyond measure to meet the needs of housing rehabilitation, giving rise to a myriad of small craft businesses and draining the manpower from other areas, particularly agriculture. This caused some interesting phenomena related to the labour market with a strong demand for workforce which the local market could not provide, thus favouring the new and hitherto unknown immigrant flows from several Italian regions and the neighbouring former Yugoslavia, anticipating the migration flows thereafter.

A third element was that the reconstruction of the countries and individual households was greatly helped and supported financially by its formal and informal network of Friulian emigrants abroad who collectively created a natural and social infrastructure and contributed significant amounts of 
money to be spent on the reconstruction of the houses, especially those typically Friulian houses with their fogolâr, fireplace, so dear to the soul of the Friulian people.

A final aspect to be noted is that, even when examining the demographic numbers more closely, the earthquake did not bring great changes, if not in the first period after the event, thus aligning later (Fig. 4) to the general trends of the region, which opened up to become permanently a region with high immigration rates now close to $10 \%$ of the residents.

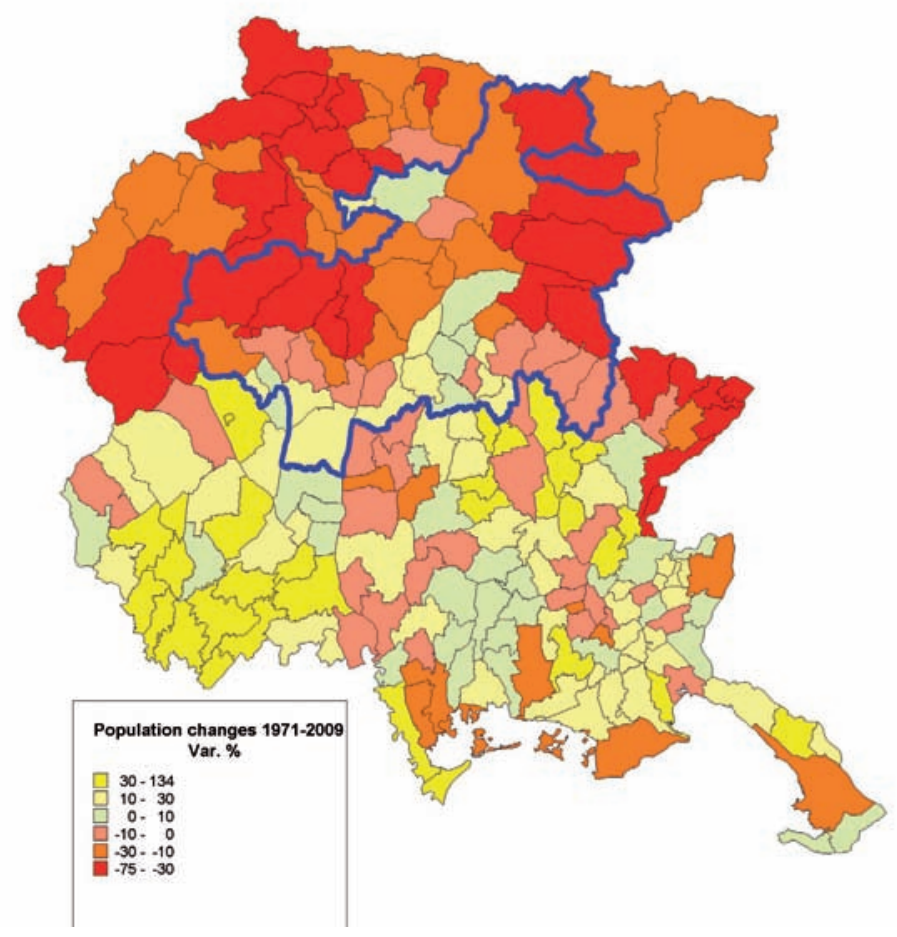

Fig. 4: Change of Number of Residents (1971-2009) Throughout the Region and the Affected Area, Var. \%.

\section{A Brief Conclusion}

The earthquake didn't change the social and economic dynamics already present in the area, but accelerated them, taking Friuli into the same direction as other Italian regions of the north-east, with the same problems related to the weakness of the most marginal areas, in this specific case due to the mountainous nature of the area, and recreating the face of the landscape, which is becoming more and more similar to the grayness of urbanization, without, however, the qualities that characterize the industrial areas.

In addition, it also contributed significantly to opening, perhaps in advance, the door to substantial migration flows into the area, which are reshaping the spatial and identity dimensions of a region that considers the earthquake as the cause of its proud rebirth.

\section{References}

Geipel, R. (1979): Friuli. Aspetti sociogeografici di una catastrofe sismica. Angeli, Milano.

Londero, I. (2008): Pa sopravivence, no pa l'anarchie. Forme di autogestione nel Friuli terremotato: l'esperienza della tendopoli di Godo (Gemona del Friuli). Forum, Udine.

Pascolini, M. (2009): Ricostruire dopo il terremoto: il «modello Friuli». In: Campione, G. (a cura di): La furia di Poseidon. Messina 1908 e dintorni. Silvana Editrice, Milano: 285-297.

Strassoldo, R. \& B. Cattarinussi (1978): Friuli: la prova del terremoto. Angeli, Milano.

Zanferrari, A. \& F. Crosilla (1997): La scienza e i terremoti. Analisi e prospettive dell'esperienza del Friuli. 1976-1996. Forum, Udine. 


\title{
Workshops
}

\section{4/1 Earthquakes in Alpine Regions - Seismic Risks}

\author{
Presentation: Hans-Peter Bunge, Joachim Wassermann \\ Input: Wolfgang A. Lenhardt, Alexander Allmann, Jan Burjánek, Martin Käser
}

Earthquakes seriously threaten society. Moderate to high seismic risks in Alpine regions result from population density, a high degree of industrialization and rather low preparedness. Due to river regulations and progress in the engineering sciences during the last two centuries, seismically unfavorable sites have become attractive for expanded settlement and industries. Future earthquakes will, therefore, cause more damage than was observed in the past. Since earthquakes strike generally without warning and exhibit relatively long return periods with strong ground shaking, the best preparation modern society can achieve is to re-enforce existing critical buildings and infrastructure as well as to change the use of land so that damage will be minimized. Areas at risk have to be recognized and mapped and reliable estimates of the expected strong ground motions must be provided to engineers and planners for the development of adequate building codes. Novel numerical simulation tools as well as new techniques of mapping shallow earth structure are currently recognized as important improvements in seismic risk assessment and mitigation. This session, therefore, focuses on both aspects: simulation and the assessment of ground motion during mid- to large-size earthquakes and their associated risk.

\section{Seismic Hazard in Alpine Regions: the Scientific View (Wolfgang A. Lenhardt)}

Earthquakes and their consequences are considered a hindrance for human settlements, especially when it comes to the planning of new power plants, reservoirs and routing or retrofitting of existing building structures. Despite this practical consideration, a better understanding of earthquake hazard and the underlying mechanisms is needed. In the Alpine region earthquakes fortunately occur less frequently when compared with other southern parts of Europe. 200 years ago, Robert Mallet, who was born in Dublin, Ireland - a country not famous for earthquakes - committed himself to studying earthquakes, and drafted the first seismicity map of the world. When comparing this map with today's, one is surprised how accurate his map actually was. Although he could put a time scale to his map - today we would term this a recurrence period - he was able to distinguish seismic from non-seismic active regions pretty accurately. Today's seismologists no longer have a problem in highlighting areas of potential seismicity. Rather they are interested in estimating details such as mechanisms, driving forces, stress drops, focal depths, magnitudes, recurrence times - and the accuracy of their estimates. The latter being a true challenge, given the paucity of data in some regions which were hardly exposed to seismicity during the recent past. It is the task of many seismologists today to delineate the levels of seismicity, and even sometimes of seismic risk in different regions. Risk - being defined as the probability of an earthquake to happen and the potential loss due to this event - is of ultimate interest for so-

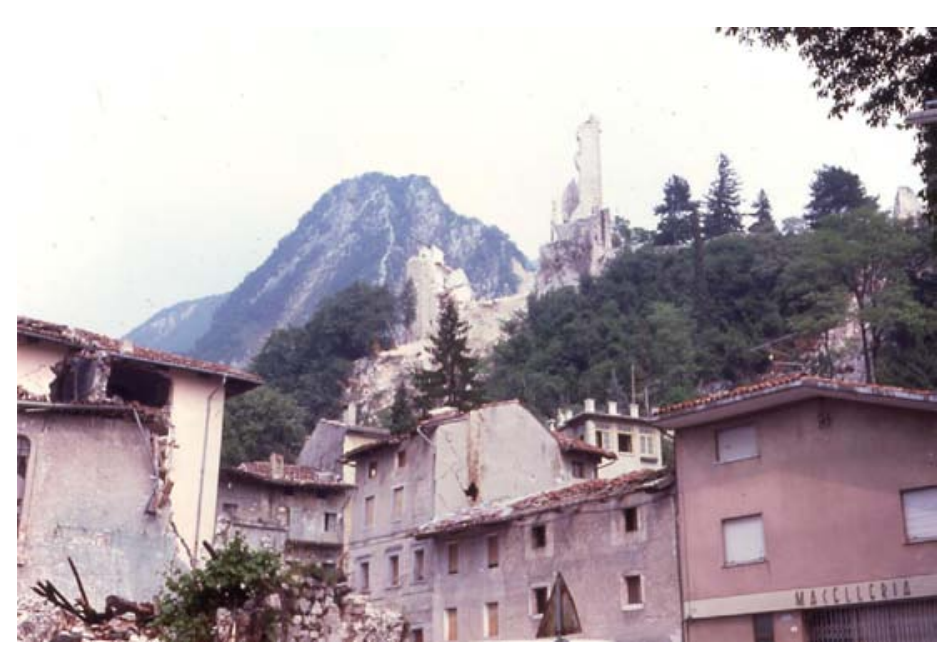

Fig. 1: Damage in Gemona di Friuli Caused by the 1976 Friulian Earthquake. 
ciety, thus having a political connotation. In order to fulfil this expectation, seismologists have been cooperating for more than a hundred years now, not only regionally but worldwide, to locate earthquakes and to determine the desired parameters which led to these events. Cross-border cooperation has gained a huge momentum in recent years, leading to international networks, of which each seismological institution is meant to be part of. The Seismological Services of Austria and Switzerland are part of the Virtual European Seismic Network (VEBSN) as many other distinguished institutions, such as those of Bavaria. Due to the occurrence of an earthquake in Bovec in Slovenia in 1998, the seismic network in Slovenia was modernized, and more recently after the earthquake in Merano on July 17 in 2001 a completely new network was set up in South Tyrol - with the help of the European Union (see figure below, triangles denote seismic stations). In addition, historical earthquake research is now being conducted in the Alpine region, involving Tyrol, South Tyrol, Veneto and Friuli, to improve the historical record of these natural catastrophes and to supplement the data determining the true seismic hazard in this region for the benefit of its population.

\section{Seismic Risk in Alpine Regions: a Reinsurance View (Anselm Smolka \& Alexander Allmann)}

The seismic risk in the Alpine and circum-Alpine region is a typical example for a low probability/ high consequence situation. The seismicity level is low to moderate, with recurrence periods of strong events for single sources counting from several hundred to more than one thousand years.
But the Friuli earthquakes of 1976 are well remembered, and there are the historical cases of Basel in 1356 and Neulengbach in the East of Vienna in 1590, which illustrate the risk posed to important urban areas in the region. Were similar events to recur today they would cause losses in the range of billions to tens of billions of euros. In order to better constrain the catastrophe potential of Alpine earthquakes, more work is needed regarding all three components constituting seismic risk: hazard, vulnerability and exposed values. For hazard this means especially geological/geophysical, historical and archeological investigations in order to assess the location, magnitude and frequency of great damaging earthquakes as well as their intensity fields. Furthermore the potential for ground motion amplification in young sedimentary basins and areas of high value concentration (e.g. Vienna basin, Rhone valley) has to be defined. Mentioning exposure may seem trivial, but in fact good and reliable inventories of buildings and infrastructure are not easy to find and their compilation usually requires a substantial effort which can be assisted nowadays by satellite-borne techniques. In respect to vulnerability the lack of empirical loss data is a problem which can be overcome only partially by the use of suitable engineering-based methods for vulnerability estimation.

Hazard and risk assessment are the first steps within the process of risk management. They serve as the basis for defining risk reduction and prevention measures on the one hand, and risk financing schemes on the other hand. In this context, earthquake insurance is actually not used to the extent which would be desirable in view of loss potentials as described above, and under a foresighted fiscal planning perspective.

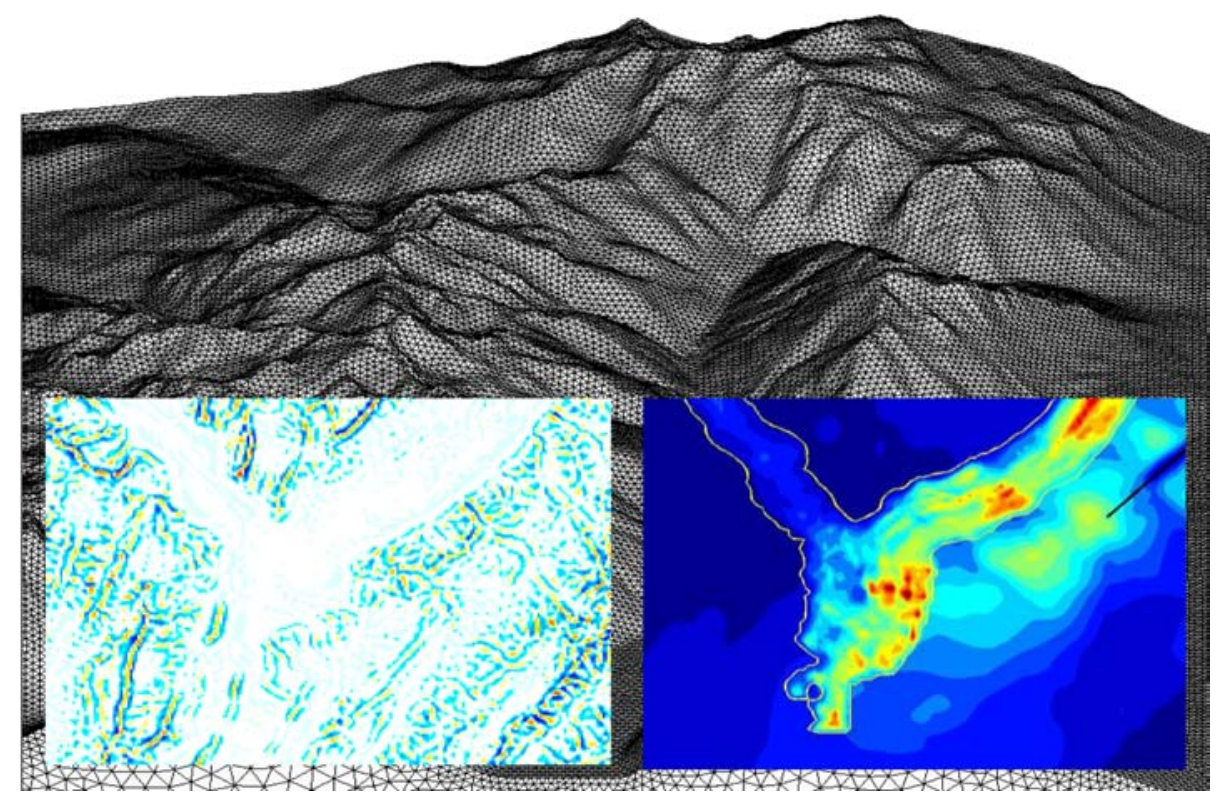

Fig. 2: Simulation of Peak Ground Acceleration Cased by Alpine Topography Using ADER DG Technique. 


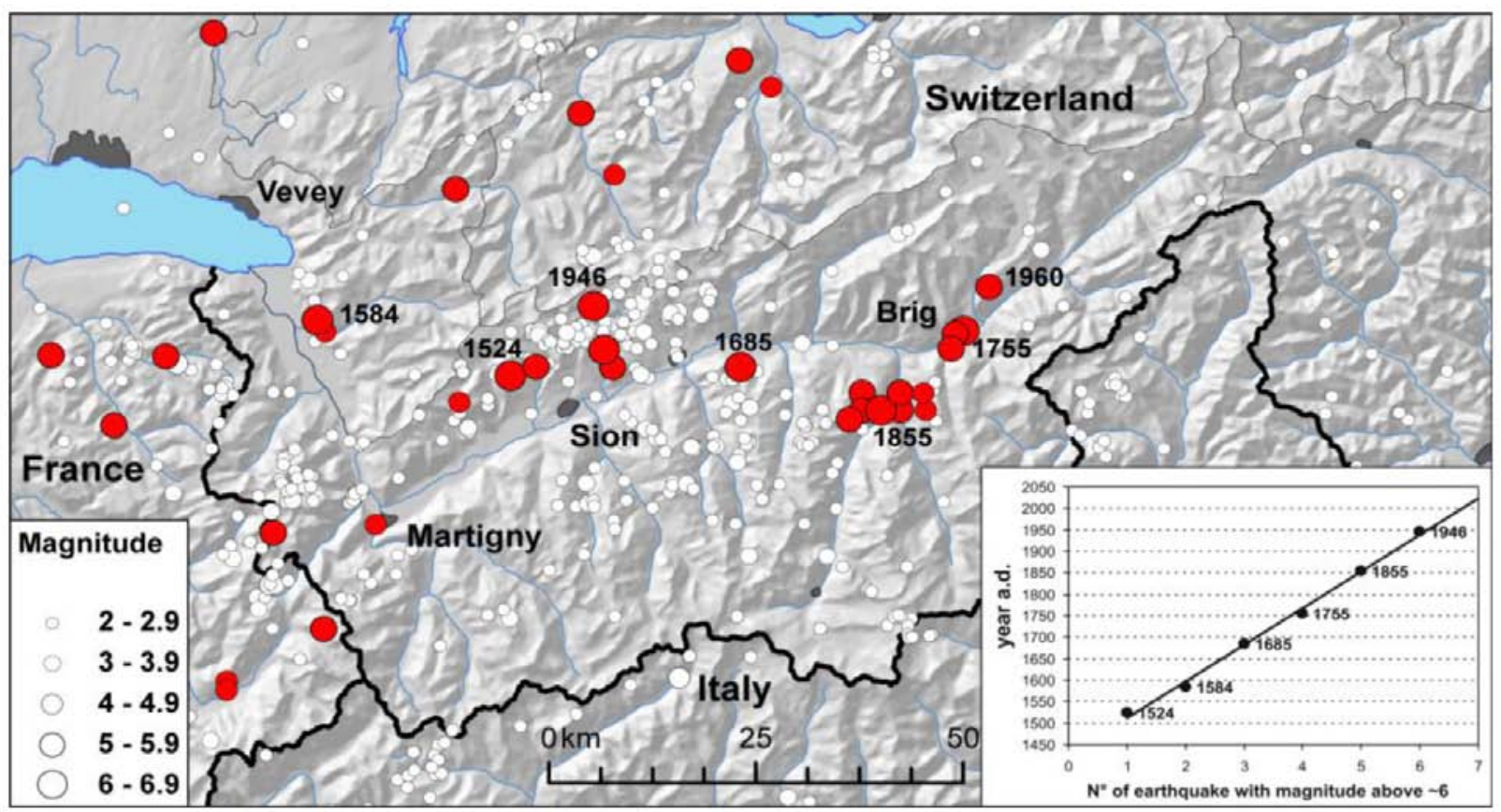

Fig. 3: Large Earthquakes in the Valais and the Timing of Magnitude 6 or Larger Historical Events.

\section{Coupled Seismogenic Geohazards in Alpine Regions (COGEAR) (Donat Fäh, Jan Burjánek, and the COGEAR Working Group)}

COGEAR is an interdisciplinary natural hazard project to investigate short and long-term earthquake preparation processes as well as complex surface effects induced by seismic strong ground motion. It addresses tectonic processes and related variability of seismicity in space and time, earthquake forecasting and observation of possible short-term precursors, and modeling and observation of weak and strong ground motion as a result of complex source and path effects. In soils and rock, we study non-linear wave propagation phenomena and liquefaction, the long-term impacts of repeated earthquakes on slope stability through rock mass strength degradation, and the triggering of landslides; the potential of earthquake-induced snow avalanches is also being estimated. Our focus is on the physics of non-linear processes in relation to topography, geological disposition, water saturation and slope stability. The consequences of earthquakes are evaluated through scenarios of direct seismic hazard and assessment of susceptibility to induced (secondary) effects.

The Valais region in Switzerland, and specifically the area of Visp, as well as the Visper and Matter valleys have been selected. In the past, the Valais has experienced every 100 years a magnitude 6 or larger event, with the last magnitude 6.1 earthquake in 1946. The region of Visp is hit by damaging earthquakes every 40 years (Intensity VI-VIII), with the last nearby event in 1960 reaching a macroseismic intensity of VIII. During all such events significant damage occurred from ground motion and different kinds of secondary phenomena such as liquefaction in the Rhone plain, slope instabilities and extended rock fall.

Our integrated approach includes detailed field investigations, the development of new probing techniques, the development and application of numerical modeling techniques, and the installation of prototype multi-sensor monitoring systems. Such systems are planned for long-term operation and will include a continuous GPS and seismic network, a test installation for observing any earthquake precursors, and two test areas (Visp, St. Niklaus-Randa) for studying site effects and non-linear surface phenomena as well as their interaction.

\section{References}

Burjánek, J., G. Gassner-Stamm, V. Poggi et al. (2010): Quantifying Slope Instability Using Ambient Vibrations. Geophysical Journal International 180: 820-828.

doi: 10.1111/j.1365-246X.2009.04451.X

Fäh, D. \& COGEAR Working Group (2008): Coupled Seismogenic Geohazards in Alpine Regions. Proceedings of the 14th World Conference on Earthquake Engineering, October 12-17, 2008, Beijing, China. Paper Number 13-0004.

Roten, D., D. Fäh, K. B. Olsen et al. (2008): A Comparison of Observed and Simulated Site Response in the Rhone Valley. Geophysical Journal International 173/3: 958-978. 


\section{Seismic Modelling Using High Performance Computing for Ground Motion Prediction in Alpine Terrain (Martin Käser, Verena Hermann, Christian Pelties)}

Ground motion prediction plays an important role in the estimation of seismic hazard. However, the accurate and reliable prediction of possible peak ground accelerations or velocities requires a detailed knowledge of the subsurface and thus the full complexity of a geological model must be considered in ground motion simulations. In particular, Alpine regions can be strongly affected by local site effects due to the accumulation of soft sediments in the valley floors. Additionally, topographic features of a rough relief can cause amplifications as well as reductions of the amplitude of ground motion amplitudes. Topography therefore is a critical issue in the model building process for numerical calculations of seismic wave phenomena in mountainous regions. We will give an overview of recent developments of the Discontinuous Galerkin (DG) Finite Element method and focus on its advantages for seismic modeling especially in Alpine terrain. We also will show the entire workflow for highly-accurate seismic simulations and highlight some of our latest results obtained by applying the DG method on modern High Performance Computing infrastructure. Numerical case studies with respect to the effects of topography and soft sedimentary basins in the Grenoble region and at Mt. Hochstaufen in southeastern Bavaria will be presented and compared to observational data to confirm the performance of our approach.

\section{References}

Chaljub, E., P. Moczo, S. Tsunoet al. (2010): Quantitative Comparison of Four Numerical Predictions of 3D Ground Motion in the Grenoble Valley, France. Bulletin of the Seismological Society of America 100,4 (in press).

Igel, H., M. Käser \& M. Stupazzini (2009): Simulation of Seismic Wave Propagation in Media with Complex Geometries. In: Encyclopedia of Complexity and System Science, edited by W.H.K. Lee, Springer Verlag.

Käser, M., M. Dumbser \& J. de la Puente (2006): An Efficient ADER-DG Method for 3D Seismic Wave Propagation in Media with Complex Geometry. In: ESG 2006, Third International Symposium on the Effects of Surface Geology on Seismic Motion 1: 455-464, Laboratoire Central des Ponts et Chaussées.

Käser, M., J. de la Puente, C. Castro et al. (2008): Seismic Wave Field Modelling Using High Performance Computing. In: SEG Expanded Abstracts 27: 2884-2888.

\title{
4/2 Landslides, Permafrost and Glaciers - Increasing Mass Movement as a Sign of Global Warming
}

\author{
Presentation: Ludwig Braun, Christoph Mayer \\ Input: Michael Eineder, Christine Rothenbühler, Kurosch Thuro
}

Mountain regions are particularly sensitive to cli-
mate change. Changes in glaciers, snow and per-
mafrost and corresponding impacts on natural
hazards in high-mountain systems could, in fact,
be among the most direct visible signals of global
warming and may seriously threaten human lives
and infrastructures in high mountain regions. Al-
though great advances in the recognition, predic-
tion and mitigation of landslides have been made
in the last few years, major events especially in al-
pine regions still claim a high social and economi-
cal tribute. Through extreme weather conditions,
as e.g. the intense rainfall in August 2005 , instable
slopes can be activated and endanger people, set-
tlements and goods in their surrounding. Recent
landslides in the Alpine region demonstrate the
need for a better understanding of the geological
and physical processes, which lead to a spontane-
ous failure of a natural slope. Major rock-slides,
such as Vajont (1963, Italy) or Randa (1991, Switzer- land), and recent minor events, such as Sibratsgfäll (1999, Austria), prove the destructive potential of these mass movements and highlight the need for a thorough investigation of the mechanics of these processes. Glacier and permafrost hazards in alpine regions include: outburst of glacier lakes, ice-avalanches, as well as destabilization of debris slopes and rock walls. The assessment of glacier and permafrost hazards requires systematic and integrative approaches. Presently, the most successful strategy is based on the combination of remote sensing, numerical modeling and local geophysical field surveys.

The workshop will address glacier and permafrost hazards and deals with various aspects of detecting, monitoring and mitigation of slope movement at different time scales. While mitigation is the overall goal, the focus of this workshop lies in the presentation of new techniques for the detection and monitoring of small to large scale mass 
movements. This includes new remote sensing techniques, as well as up-to-date developments in precise ground based point measurements.

\section{Remote Sensing of Mountain Regions with Space- Borne Radar (Michael Eineder)}

Since the year 1991 imaging radar systems are continuously operated on satellites for monitoring the earth. They work reliably day and night and even under cloudy or rainy conditions. The resolution of the established radar systems (e.g. ERS-1/2, ENVISAT/ASAR) is on the order of 25 meters, which is well suited for global applications, but of limited use when it comes to regional monitoring, for example of alpine valleys.

In the year 2007 Germany launched TerraSAR-X, the first instance of a new generation of SAR satellites for high resolution monitoring and mapping. The image raster of 1-3 meters, the X-band wavelength and the revisit cycle of 11 days are now much better suited to regional applications. The TerraSAR-X mission is carried out under what is known as a public-private partnership between the German Federal Ministry of Education and Research (Bundesministerium für Bildung und Forschung; BMBF), the German Aerospace Center (DLR) and Astrium GmbH, DLR.

The operation of TerraSAR-X is a success story since its launch and a great number of application exam- ples have been demonstrated since. Application areas with high relevance for alpine regions are:

- measurement of mountain topography and its changes

- measurement of glacier extent and glacier motion vector field

- measurement of tectonic changes

- detection of larger landslides

- measurement of creeping landslides with millimetric accuracy

- structural monitoring of larger infrastructure such as bridges, dams and buildings

Focusing on the above topics, the talk summarizes what satellite radar can accomplish today and outlines what could be done specifically for alpine regions in the future.

\section{References}

Adam, N., A. Parizzi, M. Eineder et al. (2009): Practical Persistent Scatterer Processing Validation in the Course of the Terrafirma Project. Journal of Applied Geophysics 69/1: 59-65.

Bamler, R., M. Eineder, N. Adam et al. (2009): Interferometric Potential of High Resolution Spaceborne SAR. Photogrammetrie Fernerkundung Geoinformation 5: 403-415. E. Schweizerbart'sche Verlagsbuchhandlung, Stuttgart.

doi: 10.1127/1432-8364/2009/0029.

Eineder, M., N. Adam, R. Bamler et al. (2009): Spaceborne Spotlight SAR Interferometry with TerraSAR-X. IEEE Transactions on Geoscience and Remote Sensing 47 (Issue 5): 1524-1535.

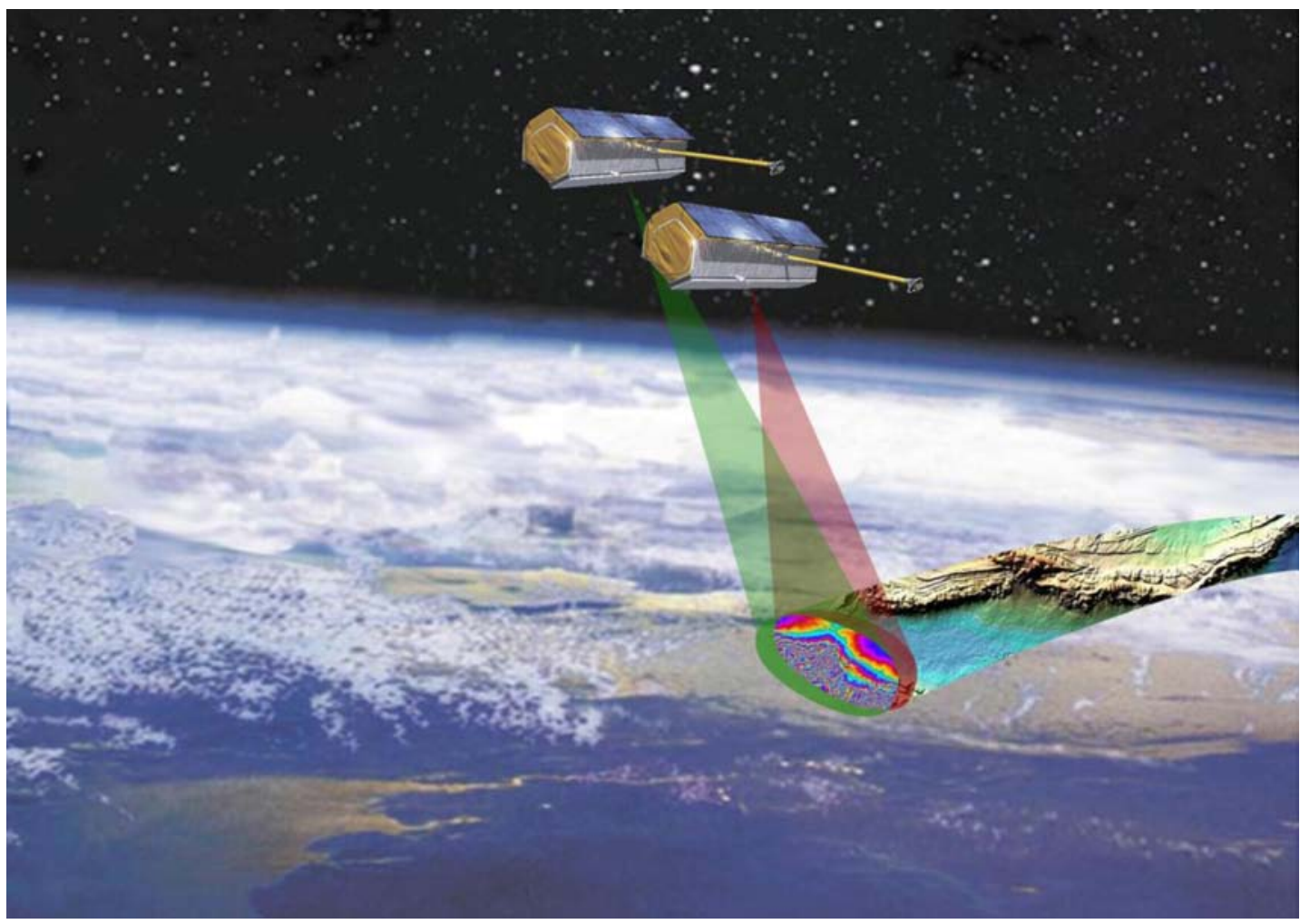

Fig. 1: With the double formation TerraSAR-X / TanDEM-X it will be possible to survey the whole surface of the earth (150 mill. $\mathrm{km}^{2}$ ) within 2.5 years (Source: EADS Astrium). 
Rabus, B., M. Eineder, A. Roth et al. (2003): The Shuttle Radar Topography Mission (SRTM) - A New Class of Digital Elevation Models Acquired by Spaceborne Radar. ISPRS Journal of Photogrammetry \& Remote Sensing 57/4: 241-262. doi: 10.1016/Sog24-2716(02)00124-7.

\section{Hazards Related to Permafrost Degradation: the Example of Pontresina (Engadine Valley, Switzerland) (Christine Rothenbühler)}

Many features in the high mountain environment such as glaciers, permafrost, vegetation or soil are very climate-sensitive and could experience large changes in the future. As a consequence, the potential starting zones for natural hazards, the dynamics of processes, the areas potentially affected by natural hazards and the attractiveness of the landscape are likely to change as well. Therefore, the high mountains can be seen as a complex system in which various features react to the rising temperatures in different time scales and intensities. The geoinformation system "GISALP" was developed to assess future changes in the Upper Engadine Valley. Several models, socalled modules, simulate the present and future distribution of landscape features and processes. The results of the modules can be visualised over a satellite image or in 3D, with the help of a digital elevation model. GISALP makes it possible for the first time to model not only one specific landscape feature or natural hazard process by itself, but it allows us to look at the landscape as a synthesis of the different processes and to visualize its reaction to rising temperatures. Considering the results of several modules, it will become possible to calculate the attractiveness of the landscape. By comparing the results from different years of one module, areas undergoing changes can be identified. A comparison of the changing areas among themselves allows statements about the speed, spatial distribution and acceleration of the changes. The results of the natural hazard modules can be overlayed with data of current infrastructure, and areas of potential future problems can be identified. In the Upper Engadine the economy depends largely on tourism, and an area with decreasing landscape attractiveness will also become a problem area. By analysing a chain of natural hazard events, it is possible to assess the effects of the combination of an ice avalanche, rushing into a glacier lake and thereby causing a debris flow, for example.

The above-mentioned methodology can be exemplified in the case of Pontresina. The slopes immediately above this tourist centre are famous for its impressive historical and recent construction work against snow avalanches and debris flows. Extensive research was carried out starting in 1989 to ensure the safety and well-being of the visitors and residents of Pontresina. So far, Pontresina has been spared from major natural catastrophes, largely on account of far-sighted investments in avalanche and landslide defence systems. Pont-

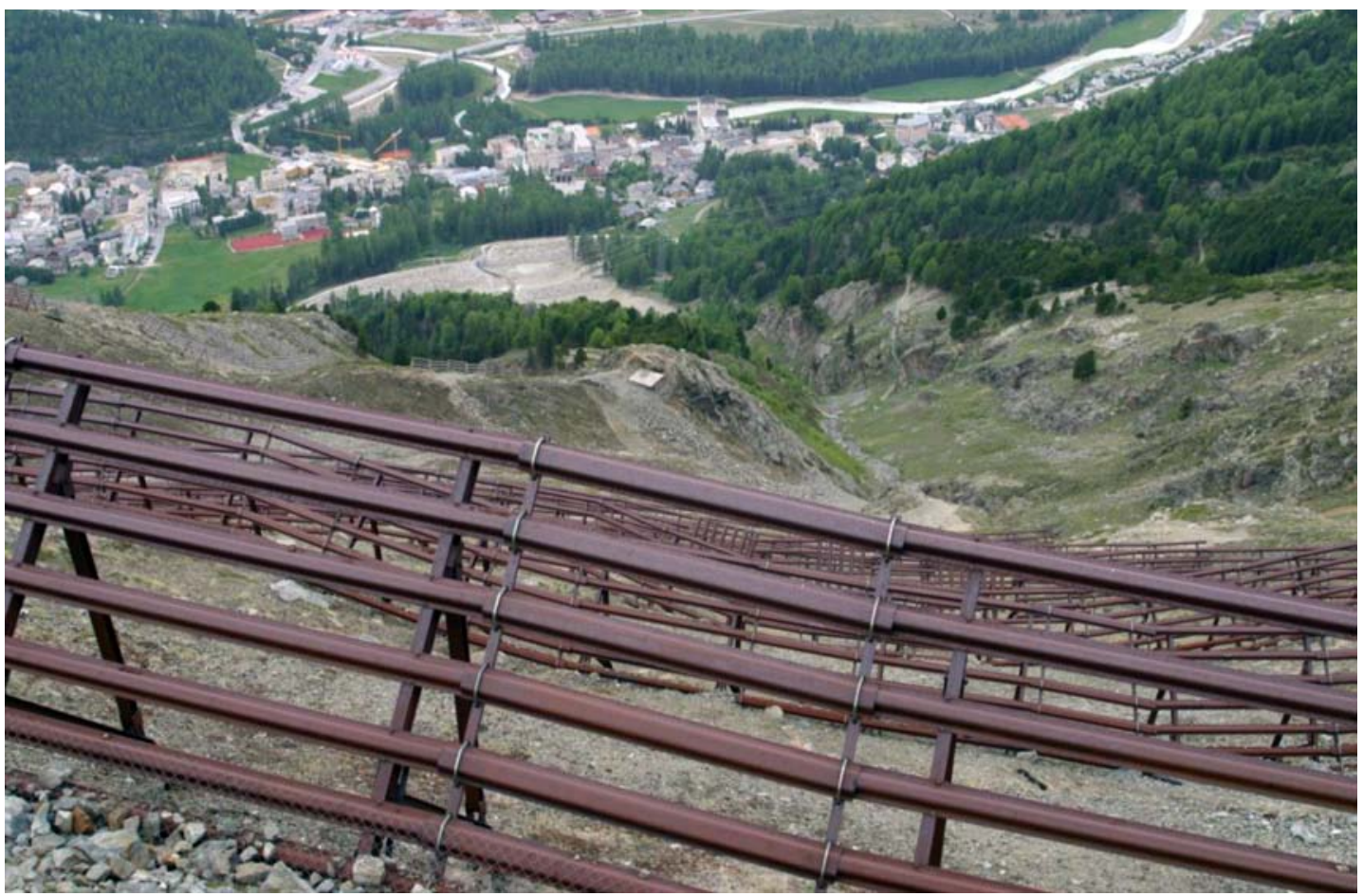

Fig. 2: Avalanche and Debris Flow Protection Above Pontresina, Engadine Valley, Switzerland.

Photo: L. Braun, 17.6.2006. 
resina began early on to address the possible effects of climate change, and today, as a pioneer in avalanche and landslide defence systems, boasts a range of comprehensive protection measures. Measurements in a more than $20 \mathrm{~m}$ deep rock glacier on Schafberg mountain above Pontresina show that its temperature is approximately at the melting point. The rock glacier is expected to thaw slowly over the coming years and decades, posing a new threat of landslides in the avalanche starting zone. The constructed dams, which blend in very well with the surrounding landscape, dispense the need to build approximately $10 \mathrm{~km}$ of avalanche defence, whilst protecting from new landslide and avalanche threats. The example of Pontresina shows how scientific investigations can help the communal government to protect the public from natural hazards related to global warming.

\section{References}

Kneisel, C., C. Rothenbühler, F. Keller et al. (2007): Hazard Assessment of Potential Periglacial Debris Flows Based on GIS-based Spatial Modelling and Geophysical Field Surveys: A Case Study in the Swiss Alps. Permafrost and Periglacial Processes 18: 259-268.

Meilwes, J., W. Haeberli, F. Keller et al. (2004): A Socio-economic and Landscape-ecological Examination of Rapidly Changing Climate-sensitive High-mountain Environments. Eco-complexity and Dynamics of the Cultural Landscape, Gießen.

Rothenbühler, C. (2006): GISALP, Räumlich-zeitliche Modellierung der klimasensitiven Hochgebirgslandschaft des Oberengadins. Studien des Institutes für Tourismus und Landschaft (ITL). Academia Engiadina, Samedan.

\section{Low Cost 3D Early Warning System for Alpine Instable Slopes (Kurosch Thuro)}

Co-leaders of the project: Thomas Wunderlich, Technische Universität München, Lehrstuhl für Geodäsie, Otto Heunecke, Universität der Bundeswehr München, Institut für Geodäsie.

In the context of global climate change and the continuous extension of settlement areas in Alpine regions, especially due to tourism, an increasing conflict between land use and natural hazard prevention can be observed. This also includes deepseated landslides, which, if activated, can cause considerable damage to settlements and infrastructure and can even endanger lives. To date, the hazard potential of slow deep-seated landslides is often underestimated. For economic reasons such potentially dangerous instable slopes are often only monitored sporadically. The alpEWAS project ("development and testing of an integrative $3 \mathrm{D}$ early warning system for alpine instable slopes") is currently developing a low-cost 3D monitoring and early warning system for landslides based on three cost-efficient and innovative continuous measurement systems: Time Domain Reflectometry (TDR) for the detection of subsurface movements in boreholes, the low-cost global navigation satellite system (GNSS), and reflectorless video tacheometry (TPS) for highly precise and extensive measurements of surface movements.

These measuring systems and further sensors, including e.g. a weather station and piezometers, are integrated into a wireless geo sensor network based on customary and therefore cost-efficient WLAN hardware. A computer centre manages all system operations, e.g. data collection and logging and controlling of the sensor nodes. The analysis of the spatially and timely highly resolved data will enable to identify correlations between triggering events (e.g. precipitation) and the movement of the landslide. This, together with numerical analyses of the landslide, will allow the definition of threshold values for the continuously monitored triggering factors, thus establishing an early warning system. In case of a likely event, the stake holders can be notified via email or SMS, enabling them to timely induce counter measures or evacuate the affected region.

In 2008 the alpEWAS geo sensor network was installed at the Aggenalm landslide (Sudelfeld, Bavaria) in order to prove the functionality and reliability of all system components (Fig. 3). To date all measuring systems and the network infrastructure are operational.

\section{References}

Singer, J., St. Schuhbäck, P. Wasmeier et al. (2009): Monitoring the Aggenalm Landslide Using Economic Deformation Measurement Techniques. Austrian Journal of Earth Sciences 102/2: 20-34.

Singer, J., K. Thuro \& U. Sambeth (2006): Development of a Continuous 3D-monitoring System for Unstable Slopes Using Time Domain Reflectometry. Felsbau 24/3: 16-23.

Thuro, K., J. Singer, J. Festl et al. (2010): New Landslide Monitoring Techniques - Developments and Experiences of the alpEWAS Project. Journal of Applied Geodesy (in print).

Thuro, K., Th. Wunderlich \& O. Heunecke, J. Singer, St. Schuhbäck, P. Wasmeier, J. Glabsch \& J. Festl (2009): Low Cost 3D Early Warning System for Alpine Instable Slopes the Aggenalm Landslide Monitoring System. Geomechanics \& Tunnelling 3: 221-237. 


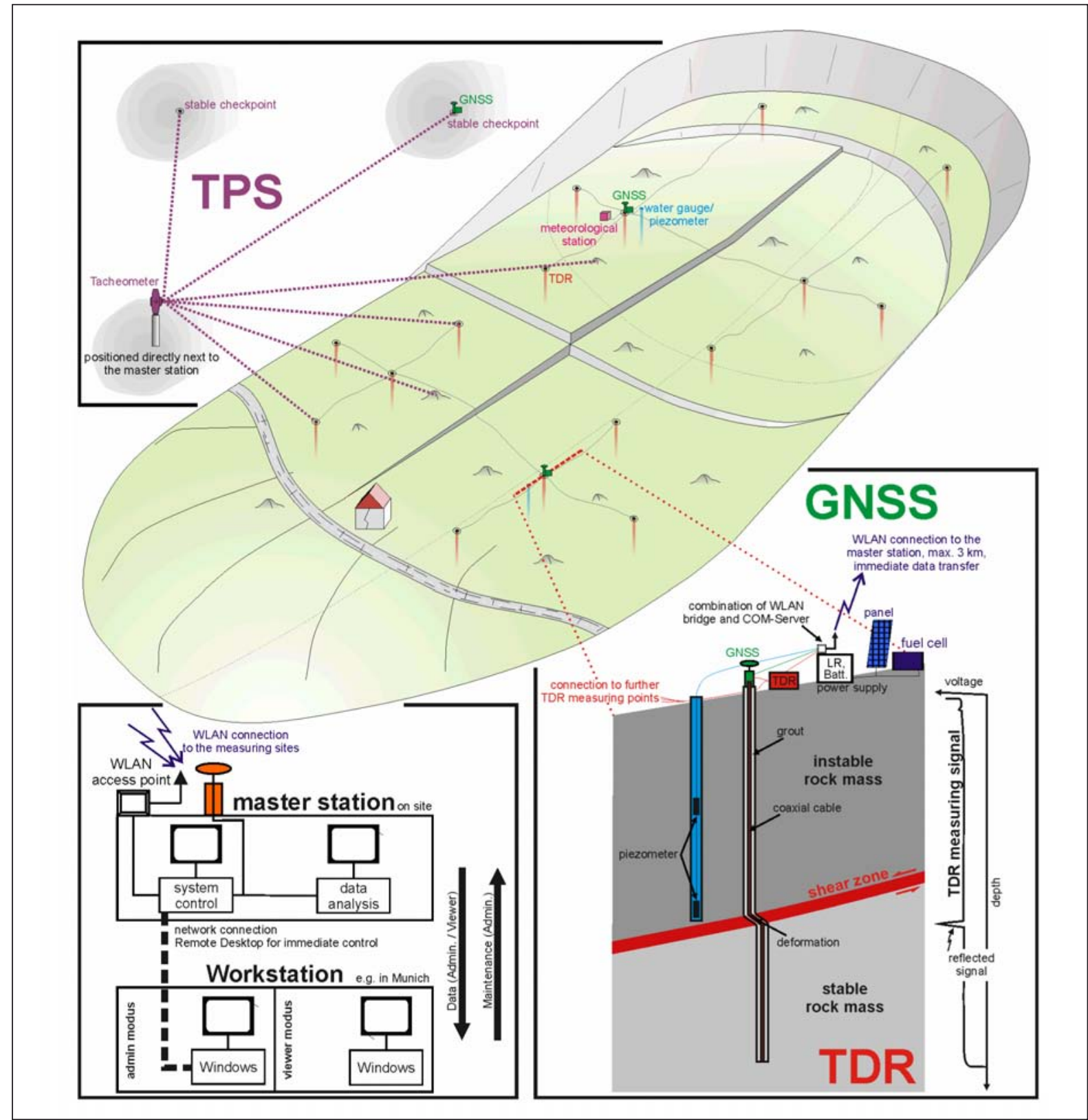

Fig. 3: Schematic Illustration of the "alpEWAS" Integrative 3D Early Warning System for Instable Slopes Currently Installed at the Aggenalm Landslide, Sudelfeld, Bavaria. 


\title{
4/3 Geothermal Technology
}

\author{
Presentation: Reinhard F. J. Hüttl \\ Input: Marco Bohnhoff, Ernst Huenges
}

Text see pp. $85-86$.

\section{4/4 Integrated Water Management in the Alps}

\author{
Presentation: Karl Schwaiger \\ Input: Andreas Rimböck, Bruno Schädler
}

Integrated water resources management covers all human activities related to use of water, protection of water and protection against hazards of water. It attempts to take into account and to harmonize these three main objectives.

Hazards of water, avoidance of these hazards as well as protection against these water related hazards has been an issue since settlement has started in the Alpine perimeter and will certainly continue to be a never ending task due to ongoing development as well as to forecasted effects of climate change. More than one billion euros of public investments are spent annually in prevention measures against damages caused by natural hazards in the Alpine perimeter (Permanent Secretariat of the Alpine Convention 2003).

While this issue has been abundantly covered in the Alps (e.g. by the Platform "Natural Hazards (PLANALP)" of the Alpine Convention and the Research Society INTERPRAEVENT which carries out interdisciplinary research on the preventive protection against disasters), the use of water as well as the protection of waters only have been gaining more attention recently, in particular with the adoption of the EU Water Framework Directive (2000/60/ EC) in 2000 and the setting up of River Basin Management Plans based on the provisions of this very Directive, respectively with the adoption of similar legislation in countries outside the European Union.

The geo-resource water is - due to the high precipitations in the region - usually available in abundance. This is why water scarcity and droughts are - apart from periodical droughts - no major issues in the Alps. This abundance of water - mostly in best quality - allows meeting the demands inside as well as outside of the Alpine perimeter for a broad range of uses inter alia:

- Water demand: Water demand in place can be met easily in terms of quantity and quality with re- gard to drinking water (examples are e.g. the drinking water supply of metropolises such as Vienna, Munich and Stuttgart coming from Alpine sources alternatively Lake Constance) respectively for other uses in industry and agriculture (Permanent Secretariat of the Alpine Convention 2009);

- Tourism: Rivers, lakes, waterfalls, glaciers in combination with the beauty of the landscape are key attractions for tourism in summer, water in form of snow as the prerequisite for winter sports is the key driver for tourism in winter;

- Hydropower generation: The steep slopes in combination with high precipitation result in perfect site preconditions for hydropower generation resulting in more than 550 large hydro power stations with a power output larger than $10 \mathrm{MW}$ and several thousands of small and micro hydropower plants. Hydropower generation is covering parts of the base loads in the consumption of electricity, but contributes in particular to cover peak demands and energy storage function, thus contributing to the stability of the transmission grid far beyond the Alpine perimeter plants (Permanent Secretariat of the Alpine Convention 2010). The reservoirs of these stations also serve other goals such as mitigations of floods and droughts (Case Study from Italy 2009).

However the manifold uses of waters as well as the protection against hazards of water have strong impacts on the ecology. Efforts are under way to remediate impacts in line with the provisions of the EU Water Framework Directive and similar legislation in place.

The workshop on "Integrated Water Management in the Alps" within the frame of "georisks and geo-resources" will be based on two brief key presentations to enhance discussions:

The first presentation "The Significance of the Alps for Downstream Hydrology and Water Resources" will highlight what is often referred to 
"Alps being the water tower of Europe" (see abstract by Bruno Schädler enclosed) and thereof resulting challenges.

In a second presentation provided by Andreas Rimböck water uses will be addressed - in line with the motto of the ForumAlpinum 2010 - which intrinsically link the Alpine perimeter with the surrounding regions and their metropolises. Particular focus will be

- on hydropower generation as this is a particular up-to-date issue against the background of energy plans adopted by countries in line with the 20-2020 goals of the European Union in order to reach a $20 \%$ share of energy from renewable sources by 2020 and

- on integrated water resource management as demonstrated by ongoing management practises of the Sylvensteinspeicher (see homepage).

\section{References}

Case Study from Italy (2009): Drought Management in the Po River Basin: Social and Economic Aspects. In: Permanent Secretariat of the Alpine Convention (2009), pp. 79-83.

http://www.wwa-wm.bayern.de/projekte und programme/ talsperren/sylvenstein/index.htm

Permanent Secretariat of the Alpine Convention (2003): Alpine Signals 1.

Permanent Secretariat of the Alpine Convention (2009): Alpine Signals - Special Edition 2, Water and Water Management Issues, Report on the State of the Alps.

Permanent Secretariat of the Alpine Convention (2010): Platform "Water Management in the Alps", Situation Report on Hydropower Generation in the Alpine Region Focusing on Small Hydropower, Draft.

\section{The Significance of the Alps for Downstream Hydrology and Water Resources (Bruno Schädler)}

Mountains and highlands typically produce substantial volumes of water. The discharge formed in mountain regions is subsequently transported to adjacent lower-lying areas via river systems. One key contributor to the importance of mountains is their ability to store winter precipitation - temporarily or over a longer period - in the form of snow and ice, which melt only in spring and summer, i.e. precisely when the water supply in the lowlands is at a minimum and agricultural demand for water is high.

Downstream, the mountain water performs important functions for the countryside and for the metropolises: for irrigation and food production, for groundwater infiltration and drinking water supply, for cooling of thermal power plants, as recipient of waste water and as medium for river navigation.

Due to their significantly higher annual discharge compared to the surrounding lowlands, the Alps are often referred to as the "Water Tower of Europe".
With a mean contribution of $34 \%$ of the total discharge, the Alpine regions of the River Rhine supply 2.3 times more water than might be expected on the basis of surface area $(15 \%)$ alone (Viviroli \& Weingartner 2004). For the River Rhone the contribution is even $41 \%$ with only $23 \%$ of share in total area, for the Po it's actually $53 \%$ (35\% share in area) and for the Danube the contribution to total discharge from the Alps is $26 \%$ (with $10 \%$ of the total area). The maximum contribution of the Alps occurs in the summer months, ranging from $36 \%$ (Danube, in August) to $80 \%$ (Po, in July). Since this summer runoff from the Alps originates from snow and ice melt, it is highly reliable and mitigates the variability of the precipitation-driven flow characteristics downstream.

Global change will increase water shortage in lowlands during summer and will modify the hydrological regime in the Alps towards more runoff in earlier seasons and lower runoff from July to October. This might lead to increased demand for water management from lowland to upstream regions: to release more water in summer for cooling, irrigation, drinking water supply and for navigation; to retain more water during flood events. It will be very important to find early enough sound solutions for a comprehensive and integrated water management within big river basins in order to avoid unrealistic expectations from downstream regions and unaccomplishable obligations in the upstream regions.

\section{References}

Viviroli, D. \& R. Weingartner (2004): Zur hydrologischen Bedeutung des Europäischen Alpenraums. In: Bundesamt für Wasser und Geologie (BWG): Hydrologischer Atlas der Schweiz (Tafel 6.4), Eidgenössische Drucksachen- und Materialzentrale (EDMZ), Bern. 
